Quim. Nova, Vol. 36, No. 8, 1194-1207, 2013

\title{
POLÍMEROS IMPRESSOS COM ÍONS: FUNDAMENTOS, ESTRATÉGIAS DE PREPARO E APLICAÇÕES EM QUÍMICA ANALÍTICA
}

\author{
Luiz Diego Marestoni \\ Instituto Federal do Paraná, Campus Telêmaco Borba, 84269-090 Telêmaco Borba - PR, Brasil/Instituto de Química, Universidade \\ Estadual Paulista, 14800-900 Araraquara - SP, Brasil \\ Maria Del Pilar Taboada Sotomayor \\ Instituto de Química, Universidade Estadual Paulista, 14800-900 Araraquara - SP, Brasil \\ Mariana Gava Segatelli \\ Departamento de Química, Centro de Ciências Exatas, Universidade Estadual de Londrina, 86050-482 Londrina - PR, Brasil \\ Lucas Rossi Sartori \\ Faculdade de Ciências Farmacêuticas de Ribeirão Preto, Universidade de São Paulo, 14040-903 Ribeirão Preto - SP, Brasil \\ César Ricardo Teixeira Tarley* \\ Departamento de Química, Centro de Ciências Exatas, Universidade Estadual de Londrina, 86050-482 Londrina - PR, Brasil/ \\ Instituto Nacional de Ciência e Tecnologia de Bioanalítica, Instituto de Química, Universidade Estadual de Campinas, 13083-970 \\ Campinas - SP, Brasil
}

Recebido em 29/1/13; aceito em 18/5/13; publicado na web em 1/7/13

\begin{abstract}
ION IMPRINTED POLYMERS: FUNDAMENTALS, PREPARATION STRATEGIES AND APPLICATIONS IN ANALYTICAL CHEMISTRY. Chemical imprinting technology has been widely used as a valuable tool in selective recognition of a given target analyte (molecule or metal ion), yielding a notable advance in the development of new analytical protocols. Since their discovery, molecularly imprinted polymers (MIPs) have been extensively studied with excellent reviews published. However, studies involving ion imprinted polymers (IIPs), in which metal ions are recognized in the presence of closely related inorganic ions, remain scarce. Thus, this review involved a survey of different synthetic approaches for preparing ion imprinted adsorbents and their application for the development of solid phase extraction methods, metal ion sensors (electrodes and optodes) and selective membranes.
\end{abstract}

Keywords: imprinting technology; preconcentration; sensors.

\section{INTRODUÇÃO}

O desenvolvimento de novos materiais tem se expandido para diversos campos do conhecimento e trazido grandes inovações em diversas áreas. Neste sentido, o estudo de novos materiais pode contribuir significativamente na área de química analítica, introduzindo maior seletividade e sensibilidade aos métodos analíticos conhecidos, por exemplo, através da variação da composição química, das dimensões físicas e da inclusão de componentes biológicos fazendo com que estes apresentem propriedades novas, o que potencializa uma ampla aplicabilidade. Tais materiais incluem os materiais híbridos, nanomateriais e materiais biomoleculares. ${ }^{1}$ Diante de uma nova realidade, na qual se tem buscado o estabelecimento de padrões de concentrações cada vez menores de poluentes em amostras de interesse ambiental, farmacêutica, clínica e alimentícia, métodos alternativos vêm sendo investigados, dentre os quais o uso de materiais adsorventes, que promovam a retenção seletiva e reversível do analito. A determinação de espécies químicas em concentrações baixas (em geral $\leq \mu \mathrm{g} \mathrm{L}^{-1}$ ) constitui, até os dias atuais, um dos grandes desafios para os químicos analíticos, apesar dos mesmos terem em mãos técnicas significativamente precisas, seletivas e sensíveis. ${ }^{2}$ Em face à concentração baixa do elemento de interesse e, ainda aos efeitos da matriz, em muitos casos torna-se uma tarefa difícil a determinação direta de concentrações baixas de analitos em amostras. Sendo assim, etapas de pré-concentração se fazem necessárias a fim de viabilizar a análise. Em determinadas situações, as etapas de pré-concentração além de conferir aumento

*e-mail: ctarleyquim@yahoo.com.br de sensibilidade do método, deve também garantir seletividade ao sistema em estudo. Isto ocorre porque, em geral, os níveis dos analitos são muito baixos, da ordem de $\mu \mathrm{g} \mathrm{L}^{-1}$, na presença de concentrações altas de concomitantes, da ordem de $\mathrm{g} \mathrm{L}^{-1}$. Sendo assim, os tratamentos prévios da amostra, conferidos por etapas de extração e/ou pré-concentração, visam eliminar o interferente e/ou pré-concentrar o analito.

As principais estratégias analíticas que atualmente permitem obter materiais seletivos, principalmente para moléculas orgânicas, baseiam-se no reconhecimento biomolecular de muitos processos biológicos. ${ }^{3}$ Nestes sistemas, as biomacromoléculas possuem sítios receptores capazes de se ligar seletivamente a uma molécula na presença de outras com estruturas análogas. Apesar destas características, deve-se ressaltar algumas desvantagens das enzimas, incluindo o elevado custo, necessidade de purificação, dificuldade de obtenção e instabilidade quando empregadas em condições diferentes daquelas de seu ambiente nativo. ${ }^{4}$ Devido a estas limitações, várias estratégias têm sido propostas no sentido de substituir os materiais biológicos por materiais sintéticos que possuam o mesmo grau de reconhecimento molecular ou, em outras palavras, o mesmo grau de seletividade. O conceito de impressão molecular em materiais sintéticos surgiu a partir de mecanismos de reconhecimento molecular, baseado em interações seletivas, tais como enzima-substrato ou antígeno-anticorpo. ${ }^{5}$ Neste sentido, materiais sintéticos, em especial os polímeros, podem apresentar efeito de impressão química, desde que interações favoráveis entre o monômero e a molécula molde ocorram durante a síntese polimérica. ${ }^{6}$ Polímeros seletivos a uma determinada molécula, preparados via tecnologia de impressão química são conhecidos como MIPs (do inglês, Molecularly Imprinted Polymers). ${ }^{7}$ 
Polímeros impressos com íons, IIPs (do inglês, Ion Imprinted Polymers) representam uma particularidade dos polímeros impressos com moléculas e possuem as mesmas virtudes dos MIPs, incluindo a simplicidade e conveniência da síntese. ${ }^{8}$

A síntese dos IIPs pode ser dividida basicamente em quatro estágios: (1) formação de um íon complexo entre o íon metálico de interesse (analito) e o monômero; (2) incorporação do íon metálico de interesse na rede polimérica ou no polímero linear por meio da reação de polimerização; (3) remoção do íon metálico impresso do polímero e (4) teste do polímero para a seletividade e religação do íon metálico de interesse. A seletividade do polímero é baseada na especificidade do ligante (no caso o monômero) em relação ao íon, na geometria de coordenação do complexo, no número de coordenação dos íons e, também, no tamanho e carga do íon. ${ }^{9}$ A Figura 1 mostra a representação esquemática da interação entre o metal de interesse e o monômero após síntese do polímero, cujo sítio seletivo é obtido após remoção do metal complexado. Na Figura 1B, nota-se que o metal se coordena com os sítios do monômero ligante e com a molécula diazo-aminobenzeno, que no caso trata-se de um agente complexante auxiliar na formação da cavidade seletiva.

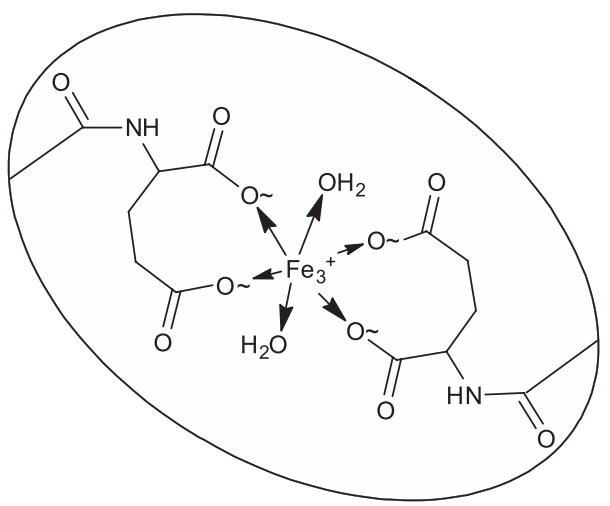

(A)

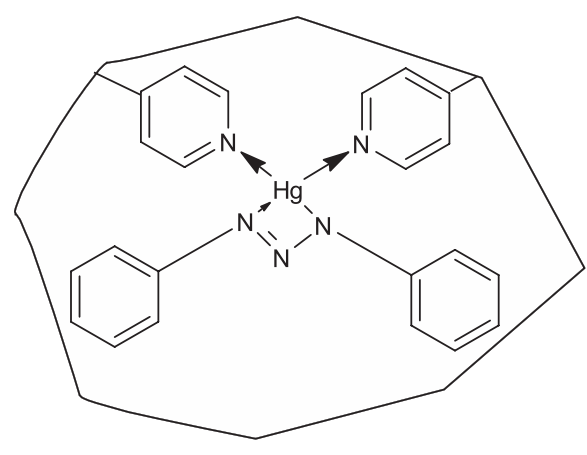

(B)

Figura 1. Representação da formação de íon complexo entre o metal e o ligante (monômero) durante a reação de polimerização do IIP. (A) monômero ligante hidroxietil metacrilato e $(B)$ monômero ligante vinilpiridina

Para avaliar a seletividade dos IIPs em relação ao analito alvo, assim como o efeito de impressão em relação ao polímero sintetizado na ausência de impressão (NIPs, do inglês Non Imprinted Polymers), comumente são realizados estudos de adsorção em batelada, empregando o IIP ou o NIP, em soluções binárias contendo o analito e o possível interferente. Os experimentos são realizados em condições de equilíbrio do analito entre a fase sólida e a líquida. $\mathrm{O}$ primeiro parâmetro determinado nestes experimentos é o coeficiente de distribuição $\left(K_{d}\right)$, o qual é obido pela equação 1 :
$K_{d_{I I P}(\text { ou NIP })}=\left[\frac{C_{i}-C_{f}}{C_{f}}\right] \times \frac{V_{s}(m L)}{\text { massa do IIP }(\text { ou NIP })(g)}$

onde $\mathrm{C}_{\mathrm{i}}, \mathrm{C}_{\mathrm{f}} \mathrm{e} \mathrm{V}_{\mathrm{s}}$ representam a concentração inicial, final e o volume da solução, respectivamente. Os valores de $K_{d}$ fornecem o grau de retenção do analito e o possível interferente nos polímeros IIP e NIP e, assim, espera-se obter valores maiores de $K_{d}$ para o analito no IIP. Porém, valores maiores de $K_{d}$ do analito no IIP podem não estar relacionados ao efeito de impressão química no polímero, mas sobretudo, devido às propriedades texturais do polímero. Desta forma, faz-se necessário determinar os coeficientes de seletividade $(k)$ e, posteriormente, o coeficiente de seletividade relativo ( $k$ ') para avaliar o efeito de impressão química no polímero. O coeficiente de seletividade é definido como a relação entre o coeficiente de distribuição $\left(K_{d}\right)$ do analito e o coeficiente de distribuição para o interferente em ambos polímeros, IIP e NIP (equação 2).

$$
k_{I I P(\text { ou NIP) }}=\frac{k_{d \text { (analito) }}}{k_{d \text { (interference) }}}
$$

Os coeficientes de seletividade $(k)$ determinados fornecem um indicativo da seletividade do IIP em relação a um determinado analito. Verifica-se que, quanto maior o valor de $k_{I I P}$, maior será a retenção do analito em detrimento ao interferente no IIP. No entanto, igualmente ao parâmetro $K_{d}$, o coeficiente de seletividade analisado isoladamente não deve ser empregado para avaliar a presença de impressão química no IIP. Para tanto, deve-se empregar o coeficiente de seletividade relativo $\left(k^{\prime}\right)$, conforme equação 3 .

$$
k^{\prime}=\frac{k_{I I P}}{k_{N I P}}
$$

A comparação do coeficiente de seletividade do IIP com o correspondente polímero controle (NIP) revela que razões acima de 1 confirmam o efeito de impressão química originado no IIP. ${ }^{10}$

As condições de síntese mais usuais dos IIPs contemplam a ausência de oxigênio, aquecimento $\left(60^{\circ} \mathrm{C}\right.$ em média $)$ e tempo de reação de $24 \mathrm{~h}$ com a polimerização em meio homogêneo, também conhecida como polimerização em bulk. É importante ressaltar que dependendo do tipo de monômero empregado na síntese, o tempo reacional e temperatura podem ser alterados. Na polimerização em $b u l k$, a reação é realizada em um sistema homogêneo de uma solução contendo monômero, analito molde, solvente porogênico, reagente de ligação cruzada e iniciador radicalar em um frasco selado com ausência de oxigênio. A polimerização é induzida com aquecimento e/ou radiação UV e o sólido obtido é triturado de maneira a permitir o acesso ao analito (para remoção e religação) e peneirado, com a finalidade de uniformizar o tamanho das partículas. No entanto, imagens de microscopia eletrônica de varredura (MEV) mostram que este tipo de polimerização resulta em partículas relativamente grandes e de tamanhos não uniformes. ${ }^{11}$ Além disso, sabe-se que o efeito de impressão, a capacidade de retenção e a seletividade destes polímeros são relativamente menores em comparação com polímeros sintetizados por meio de outras técnicas de polimerização, como demonstrado para o paládio no trabalho de Daniel. ${ }^{12}$ A fim de se evitar a formação de uma matriz polimérica rígida e a consequente etapa de moagem, pode-se alternativamente utilizar volumes superiores de solvente porogênico (acima de 5 vezes em relação o procedimento em bulk), caracterizando um processo de síntese denominado de precipitação. Outra possibilidade de síntese é a polimerização por suspensão, que é pautada em reações que ocorrem entre os monômeros dispersos num solvente imiscível no meio reacional. Neste processo 
de polimerização, utiliza-se um agente estabilizador, cuja função é evitar a coagulação das gotas dos monômeros durante o processo, $\mathrm{o}$ que faz com que o polímero seja produzido no formato de esferas.

O primeiro trabalho desenvolvido com IIP foi publicado na década de 70, onde Nishide e Deguchi utilizaram poli(vinil-piridina) para extração de íons metálicos. ${ }^{13} \mathrm{Na}$ Figura 2 verifica-se o número de publicações contendo a palavra chave "ion imprinted polymer", onde se pode observar que na última década houve uma evolução exponencial do conhecimento na área de polímeros impressos com íons, o que demonstra um interesse crescente do mercado para utilização destes materiais. ${ }^{14}$ Uma aplicação comercial particularmente promissora de polímeros impressos com íons é a utilização como material extrator em fase sólida para determinação de metais em níveis traço, ou como material para separação de espécies coexistentes em matrizes complexas. Cabe mencionar que polímeros molecularmente impressos são disponíveis comercialmente. Para aplicação dos IIPs em sensores, existe ainda um amplo caminho a ser percorrido, visto que os polímeros impressos com íons, por não serem condutores em sua grande maioria, resultam em dispositivos com baixo desempenho seletivo e sensível no transdutor. ${ }^{11}$ No entanto, a associação de IIPs com nanopartículas metálicas ou materiais eletródicos eficientes, como nanotubos de carbono, bem como a avaliação de novos polímeros condutores é uma tendência a ser explorada.

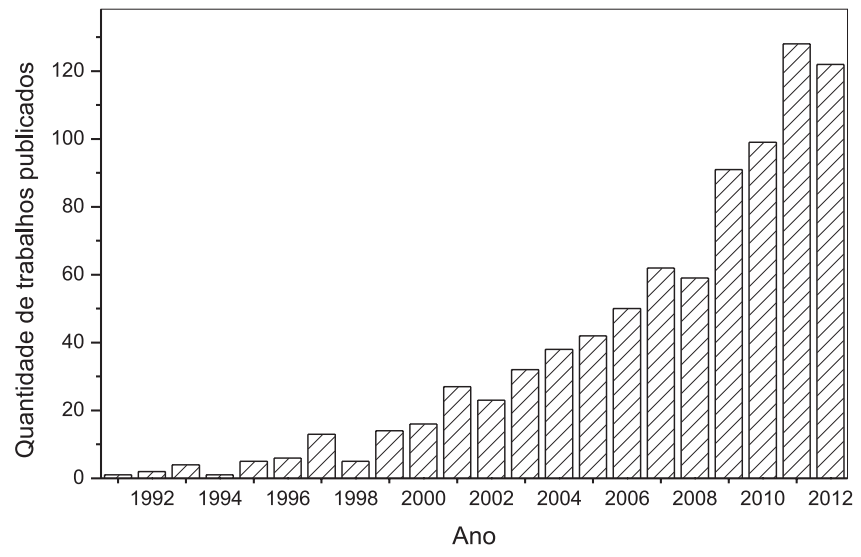

Figura 2. Número de publicações anuais envolvendo IIPs (período janeiro 1991 até 31 de dezembro de 2012) ${ }^{14}$

O objeto principal deste trabalho é divulgar o estado da arte no preparo dos IIPs de maneira a fornecer um material acessível, onde as tendências poderão ser identificadas em trabalhos previamente publicados, criando assim possibilidades para o desenvolvimento de novos métodos analíticos, sobretudo, com seletivitidade e sensibilidade melhoradas.

\section{POLÍMEROS ORGÂNICOS IMPRESSOS COM ÍONS}

Os primeiros trabalhos desenvolvidos com IIPs foram realizados usando os polímeros orgânicos, sendo eles: poli(etilenoimina), poli(vinilpiridina), álcool poli(vinílico) e poli(acrilato) para reco-

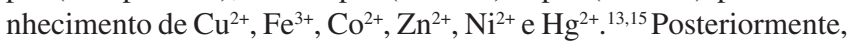
muitos trabalhos foram realizados para obtenção de IIPs para outros íons. A predominância dos trabalhos envolvendo a síntese de íons com polímeros orgânicos descreve o uso do 2,2'-azobisisobutironitrila (AIBN) como iniciador radicalar e o divinilbenzeno (DVB) ou etilenoglicoldimetacrilato (EDGMA) como reagentes reticulantes.

IIPs orgânicos são utilizados em extração em fase sólida (IIP$\mathrm{SPE}$ ), podendo a síntese ser resumidamente classificada em quatro abordagens, e baseadas na forma como os ligantes são imobilizados na matriz do polímero, sendo elas: a reticulação de polímeros de cadeia linear que possuem grupos de ligação para metais utilizando um reagente bifuncional; a imobilização química pela preparação inicial de complexos binários dos íons metálicos com ligantes contendo grupos vinila, com posterior isolamento do complexo formado e polimerização com os monômeros formadores da matriz; $\boldsymbol{a}$ impressão superficial realizada em interfaces orgânica - aquosa; e a síntese por aprisionamento de ligantes quelantes não vinilados, via impressão de complexos ligantes mistos binários/ternários dos íons metálicos com agentes quelantes não vinilados e ligantes vinilas. Além da extração em fase sólida, os IIPs também podem ser empregados em membranas de separação e em sensores para quantificação de íons metálicos, que será discutida em secção específica.

O método de síntese que emprega os polímeros orgânicos de cadeias lineares é o pioneiro na preparação de IIPs orgânicos e se caracteriza pela reticulação entre reagentes bifuncionais, tal como nos trabalhos realizados pelo grupo de Nishide, ${ }^{13,15}$ em que a poli(4-vinilpiridina) previamente preparada foi reticulada com 1,4-dibromobutano na presença de íons metálicos e como no grupo de Kabanov, ${ }^{16}$ no qual o polímero formado pelo dietilvinilfosfonado e o ácido acrílico foi reticulado com $N, N$-metilenodiacrilamida na presença de íons metálicos. Ohga e colaboradores prepararam um IIP com quitosana e epicloridrina que permitiu separar $\mathrm{Cd}^{2+}$

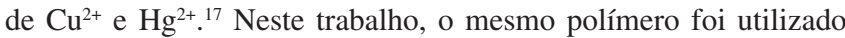
diversas vezes, apresentando um resultado satisfatório em termos de precisão e reutilização. Estes polímeros impressos apresentam alta capacidade de ligação para os íons impressos, entretanto, não possuem boa seletividade, o que resultou em desuso da técnica e consequentemente poucas publicações em relação à quantidade total de trabalhos publicados. A baixa seletividade destes polímeros está associada ao efeito de impressão pouco pronunciado, uma vez que não há formação do complexo entre o íon metálico e o monômero antes da etapa de polimerização.

Os IIPs sintetizados explorando a formação prévia de um complexo metálico com o monômero, com posterior polimerização na presença de um agente de ligação cruzada, apresentam seletividade maior comparada àquela dos polímeros com cadeias lineares. Neste caso, é necessária a utilização de monômeros ligantes vinilados que são imobilizados à matriz do polímero, permitindo que o ligante permaneça fortemente ligado ao polímero reticulado, de maneira a formar quelatos, ou seja, neste caso os íons são mais fortemente ligados a matriz, devido à predominância de ligações de coordenação. Em 1981, Kato e colaboradores foram os primeiros a utilizar a síntese de IIPs utilizando agentes de ligação cruzada. ${ }^{18}$ Neste trabalho o 1-vinilimidazol foi copolimerizado com 1-vinil-2-pirolidona e DVB na presença de $\mathrm{Cu}^{2+}, \mathrm{Ni}^{2+}$ ou $\mathrm{Co}^{2+}$.

Estudando a separação de lantânio e gadolínio, Garcia e colaboradores avaliaram vários monômeros a fim de maximizar a eficiência do polímero. ${ }^{19}$ Os resultados mostraram que a copolimerização utilizando o acido acrílico foi a mais eficiente, além de terem estudado a influência do agente reticulante e do agente complexante..$^{20}$ Recentemente, Fasihi e colaboradores utilizaram o 1-hidroxi-2-(2'-propenila)-9,10antraquinona como ligante vinilado para reconhecimento de urânio. ${ }^{21}$ O material apresentou rápida cinética de ligação e transferência de massa, sendo adequado para uso em soluções com pH entre 4,0 e 7,0; mostrando superfície homogênea com capacidade de ligação melhor que o respectivo polímero não impresso, além de exibir boa seletividade em relação a outros metais com propriedades periódicas semelhantes. Tais trabalhos demonstram a importância da otimização dos parâmetros da síntese.

Na ultima década Ersöz e colaboradores desenvolveram um método para extração seletiva de íons $\mathrm{Ni}^{2+}$ utilizando espectrometria de absorção atômica em chama (FAAS) para determinação da seletividade e da capacidade máxima de adsorção do polímero. ${ }^{8} \mathrm{O}$ polímero 
foi sintetizado com histidina hidratada metacrílica como monômero ligante e EGDMA como reagente de ligação cruzada. Obteve-se um limite de detecção para extração de $0,3 \mu \mathrm{g} \mathrm{L}^{-1}$ com linearidade da curva de calibração até $25,0 \mu \mathrm{g} \mathrm{L} \mathrm{L}^{-1}$ e $k^{\prime}$ para $\mathrm{Ni}^{2+} / \mathrm{Cu}^{2+}, \mathrm{Ni}^{2+} / \mathrm{Zn}^{2+}$ e $\mathrm{Ni}^{2+} / \mathrm{Co}^{2+}$ de $57,3,53,9$ e 17,3 , respectivamente, o que demonstra a aplicabilidade da técnica. Em outros dois trabalhos, o mesmo autor e colaboradores desenvolveram um método para extração de $\mathrm{Cu}^{2+} \mathrm{e}$ $\mathrm{CN}^{-}$utilizando um meio de dispersão de álcool poli(vinílico) em água; nestes casos obteve-se $k^{\prime}$ com valores de 43,37 a 167,9. ${ }^{8,22}$

Os IIPs preparados pela técnica de impressão superfícial envolvem a polimerização heterogênea em meio aquoso (emulsão) utilizando um monômero funcional, um estabilizador da emulsão, um co-monômero formador da matriz polimérica e a analito molde. Esta técnica está baseada na modificação da superfície da matriz do material polimérico. A distribuição das cavidades impressas em uma fina camada do polímero na matriz do material representa uma grande vantagem para a rápida ligação do íon molde com os sítios de reconhecimento. O processo de síntese é apresentado na Figura 3 e segue os seguintes passos: (1) a molécula molde é adicionada ao monomero funcional, que é anfifílico por natureza até atingir a saturação que ocorre na interface óleo-água; (2) a polimerização ocorre na fase anfifílica com adição do agente de ligação cruzada; (3) após a remoção do analito molde, as cavidades seletivas ficam expostas na superfície da partícula polimérica.

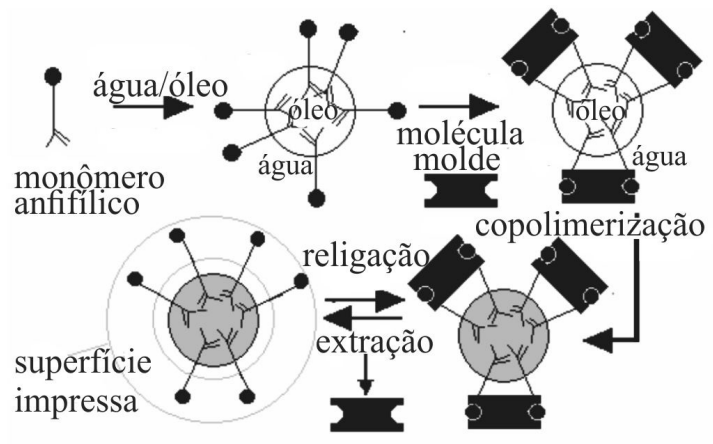

Figura 3. Técnica de impressão superficial em meio água/óleo (formador da superfície de polimerização). A terminação dos monômeros na fase óleo é polimerizada de maneira a formar uma resina, com superficie (inicialmente na fase aquosa) impressa

O trabalho que apresentou inicialmente esta técnica foi publicado em 1992 por Kido e colaboradores..$^{23}$ Entre as vantagens da técnica incluem-se a cinética de ligação rápida e a facilidade em lidar com impressões de íons hidrofílicos. Assim, uma série de trabalhos têm sido publicados usando esta técnica, por exemplo, para os íons $\mathrm{Co}^{2+}$, $\mathrm{Ni}^{2+} \mathrm{eCu}^{2+}$ com microesferas impressas preparadas por polimerização em emulsão por sementes, que são obtidas utilizando estireno, divinilbenzeno, burilacilato e ácido metacrílico em água. ${ }^{24}$ Uma forma bastante comum de polimerização é por irradiação, pois resulta em uma matriz polimérica mais rígida, uma vez que o monômero funcional se liga mais fortemente à matriz. ${ }^{25}$ Além destes, outros trabalhos foram desenvolvidos para reconhecimento de $\mathrm{Zn}^{2+}$ explorando IIPs preparados por impressão superficial, onde pode-se verificar que a mudança do monômero DVB pelo trimetilopropanotrimetacrilato (TRIM) confere uma alta rigidez à matriz polimérica resultante. ${ }^{26,27}$ Recentemente Liu e colaboradores utilizaram sílica mesoporosa para melhorar a impressão superficial de $\mathrm{Pb}^{2+}$ e obtiveram êxito na cinética de ligação, na seletividade e na capacidade de absorção. ${ }^{28} \mathrm{Li}$ e colaboradores desenvolveram um método simples para impressão superficial de $\mathrm{Cu}^{2+}$ em que o poli(glicidilmetacrilato) foi introduzido em fibras de polipropileno de maneira a agir como um ligante. ${ }^{26}$
Entretanto, muitos estudos ainda devem ser realizados com intuito de aperfeiçoar as propriedades seletivas dos polímeros preparados pela técnica de impressão superfícial, pois em alguns casos os IIPs apresentam capacidade de retenção semelhantes aos NIPs, além de apresentarem baixa seletividade. ${ }^{29,30}$

Os IIPs sintetizados por aprisionamento se baseiam na polimerização de monômeros vinilados que realizam ligações químicas com íon molde e com a matriz do polímero, via o grupo vinila, e agentes complexantes não vinilados, que reagem somente com íon molde, mas que, ao término da polimerização, são aprisionados dentro da matriz polimérica. As interações específicas entre o grupo funcional (presente no monômero e no agente complexante) conferem seletividade ao polímero. Nesta técnica, os IIPs são preparados via polimerização térmica por copolimerização do complexo ternário com ligantes mistos, tal como realizado para obter IIPs seletivos a disprósio, érbio e neodímio. ${ }^{31}$ Nestes trabalhos, empregaram-se os íons complexos ternários, 5,7-dicloroquinolina-8-ol (DCQ) e 4-vinilpiridina (4-VP), estireno como monômero, DVB como reagente de ligação cruzada e AIBN como iniciador radicalar. Na base de patentes americanas pode-se encontrar um depósito em que Ramakrishna e colaboradores desenvolveram um polímero para pré-concentração do íon érbio, o que mostra a aplicabilidade comercial dos IIPs. ${ }^{32}$ Quanto à influência dos agentes reticulantes para esta síntese, foi verificado que alguns desempenham melhores resultados quando polimerizados por irradiação $\gamma$, como segue: estireno-DVB $>2$ hidroxietilmetacrilato-EGDMA $>$ metacrilato de metila-EGDMA. ${ }^{33}$ Muitos são os trabalhos com IIPs sintetizados por aprisionamento para separação de íons urânio em amostras de solos e sedimentos, em água do mar e em combustíveis nucleares. ${ }^{30,34}$ Gladis e Rao, em 2004, estudaram o efeito de diferentes solventes porogênicos para síntese de IIPs para urânio e concluíram que o polímero preparado com o solvente 2-metoxietanol apresenta maior capacidade de retenção, absorção e melhor seletividade para o urânio sobre o tório. ${ }^{35} \mathrm{Em}$ relação aos agentes quelantes, pode-se observar melhor sinergismo na utilização de dicloroquinolina e o ácido succínico e 4-VP como monômero, devido à melhor recuperação, enquanto que o quelante catecol apresentou o resultado menos satisfatório. ${ }^{36}$

Para reconhecimento do íon paládio foi realizado o isolamento do complexo paládio-dimetilglioxima (DMG), dissolvido no solvente porogênico ciclohexanol, copolimerizado com DVB após a formação com o complexo ternário com VP, o que resultou em um IIP 100 vezes mais seletivo que o NIP, além de um baixo limite de detecção de 2,5 $\mu \mathrm{g} \mathrm{L}{ }^{-1}$, utilizando espectrofotometria UV-Vis. ${ }^{37}$ Em outro trabalho dos mesmos autores foram avaliados os efeitos de impressão, extração, retenção e seletividade usando os métodos de polimerização em bulk, precipitação e suspensão, onde foi verificado que o método em bulk e de precipitação apresentaram resultados melhores que o método de suspensão. ${ }^{12}$ Existem ainda diversos trabalhos para outros íons utilizando-se a síntese por aprisionamento, como para os íons $\mathrm{Hg}^{2+}$, $\mathrm{Cd}^{2+}$ e $\mathrm{Cu}^{2+} .{ }^{38-40}$ De maneira geral, IIPs obtidos pela técnica de aprisionamento apresentam alta capacidade de retenção, coeficiente de seletividade e efeito de impressão mais evidente quando comparada com as outras técnicas de síntese apresentadas. ${ }^{30}$

Entretanto, a adoção de um procedimento de síntese em detrimento a outro deve ser cuidadosamente avaliada tendo em vista o tipo de aplicação posterior do polímero. Cita-se o trabalho de OteroRomani, em que o IIP polimerizado pela técnica de aprisionamento visando a extração seletiva de $\mathrm{Ni}^{2+}$ apresentou grande capacidade de retenção de 70 a $100 \%$. ${ }^{29}$ Porém, quantidades elevadas de $\mathrm{Cu}^{2+}, \mathrm{Pb}^{2+}$ e zinco foram também extraídas quando o polímero foi aplicado em amostras de água do mar. Neste caso, os autores sugerem que o uso do agente complexante 8-hidroxiquinolina deve ter influenciado a baixa seletividade. 
As membranas de separação surgiram para tentar superar as dificuldades encontradas em relação à baixa uniformidade das partículas das técnicas apresentadas. Existem três métodos principais para a preparação de uma membrana adsorvente: (1) preparação da membrana a partir de um IIP previamente sintetizado "convencionalmente"; por exemplo, na disposição do IIP entre as duas membranas de microfiltração, funcionando como um recheio; (2) síntese do IIP na forma de uma membrana. Neste caso, deve-se atentar para a produção de membranas com a espessura de pelo menos $10 \mu \mathrm{m}$, pois espessuras menores são instáveis química e fisicamente, e para a "sincronização" entre o efeito de impressão e solidificação da membrana, estes são de suma importância para a forma, estrutura e função da membrana; (3) síntese do IIP dentro ou sobre uma membrana suporte com morfologia adequada, onde os poros da membrana suporte são funcionalizados com uma fina camada seletiva (IIP). ${ }^{41}$ A principal característica desta técnica é de produzir filmes poliméricos impressos que possibilitem utilizá-los como materiais de filtração para a separação seletiva. ${ }^{42}$ Kimaro e colaboradores utilizaram uma membrana seletiva para separação de urânio via polimerização em $b u l k .{ }^{43}$ Araki e colaboradores produziram uma membrana seletiva a $\mathrm{Zn}^{2+}$ utilizando água em óleo como emulsão de polimerização. ${ }^{44}$ Murray depositou patente para um IIP por membrana seletiva para remover íons fosfato, nitrato e férricos, o que também enaltece uma possível aplicabilidade prática da síntese ${ }^{45}$ Tais trabalhos têm mostrado que as membranas impressas apresentam coeficiente de seletividade relativa acima de 1 . No entanto, se apresentam como uma técnica ainda a ser explorada, visto que são apresentados poucos resultados satisfatórios quanto à capacidade de retenção e coeficientes de seletividade.

\section{POLÍMEROS INORGÂNICOS IMPRESSOS COM ÍONS}

Polímeros inorgânicos impressos com íons também contemplam o campo de aplicação tecnológica da impressão química. Estes polímeros possuem as mesmas finalidades que os polímeros orgânicos, ou seja, estabelecer uma adsorção mais seletiva por um íon em detrimento a outros presentes na amostra. Basicamente, os polímeros inorgânicos são comumente sintetizados por meio do processo sol-gel, empregando-se tetraetoxissilano (TEOS) como agente reticulante e responsável pela formação da rede polimérica. ${ }^{46}$

Na Figura 4 é apresentada uma rota sintética sistemática para a formação de um IIP inorgânico seletivo ao íon $\mathrm{Cd}^{2+}$. De acordo com a Figura 4 deve-se adotar inicialmente um precursor funcional que estabeleça forte ligação com o íon metálico. Além de este precursor possuir sítios de ligação capazes de se ligar ao íon metálico, o mesmo também deve conter sítios de ligação responsáveis pela reação de copolimerização com o agente de ligação cruzada. No exemplo, foi empregado o precursor funcional 3-(2-aminoetilamino)-propiltrimetoxissilano (AAPTS), enquanto o TEOS foi usado como agente reticulante.

Para formação do polímero impresso com íon via processo sol-gel, inicialmente, a reação deve ocorrer entre o íon metálico e o grupo seletivo do precursor funcional. Em seguida, TEOS e os grupos trimetoxi do precursor funcional são hidrolisados em temperatura controlada. Posteriormente, ocorre a autocondensação dos compostos hidrolisados seguido de copolimerização, resultando em uma cadeia polimérica inorgânica contendo na cavidade seletiva o íon metálico ligado aos sítios do precursor funcional. Ácidos ou bases podem ser utilizados como catalisadores na síntese. A utilização de catalisadores ácidos leva à formação de partículas com tamanhos menores, o que leva a uma maior área superficial, e menor agregação. No entanto, o polímero resultante exibe estabilidade reduzida e, caso exista excesso de catalisador, conduz apenas a formação de uma estrutura microporosa. A catálise básica, por outro lado, resulta em estruturas

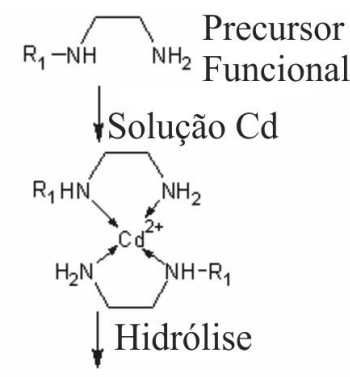

$$
\begin{aligned}
& \mathrm{R}_{1}=\mathrm{Si}\left(\mathrm{OCH}_{3}\right)_{3} \\
& \mathrm{R}_{2}=\mathrm{Cd}^{2+} \quad \text { Complexo }
\end{aligned}
$$$$
\text { Agente Reticulante }
$$

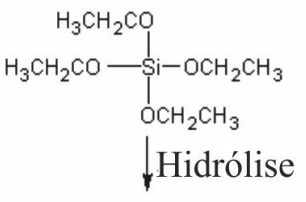

$\mathrm{HO}-\stackrel{\mathrm{OH}}{\mathrm{I}} \underset{\mathrm{S}-\mathrm{R}_{2}-\mathrm{I}_{\mathrm{I}}}{\mathrm{OCH}_{3}}-\mathrm{OH}$<smiles>O[Si](O)(O)O</smiles>

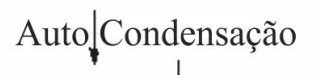

Auto|Condensação

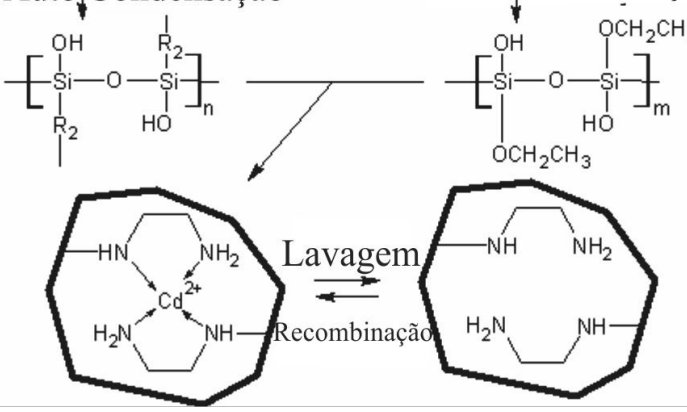

Figura 4. Rota esquemática da síntese e mecanismo de reconhecimento do ion de um polímero impresso pelo processo sol-gel. Adaptada da ref. 53

mesoporosas, contudo, não cristalinas, o que requer altas temperaturas de calcinação para cristalização, durante o qual a forma mesoporosa é reduzida, além de apresentar cristais maiores, pequena área superficial e alta agregação entre as partículas. ${ }^{47}$ Desta forma, a catálise ácida tem sido mais utilizada para a síntese de polímeros inorgânicos.

Como constatado, os polímeros inorgânicos se diferenciam daqueles orgânicos no tocante aos diferentes monômeros empregados e a estratégia sintética, pois não é necessário empregar iniciadores radicalares. Além disso, a síntese pode ser efetuada na presença de oxigênio com aquecimento de $90{ }^{\circ} \mathrm{C}$ em média e em um tempo de reação bastante elevado, cerca de dois dias sob refluxo. ${ }^{48}$

Conforme já mencionado, os IIPs orgânicos quando sintetizados pelo método de polimerização em bulk apresentam estruturas poliméricas desfavoráveis para a rápida transferência de massa do analito para o polímero, resultando em uma cinética lenta de retenção. ${ }^{48}$ Esta constatação evidencia que, de maneira geral, outros procedimentos de síntese, tais como suspensão e precipitação, são mais convidativos para emprego dos IIPs em propostas analíticas de extração de metais usando sistemas em fluxo. Em relação aos IIPs inorgânicos preparados pelo processo sol-gel, sabe-se que tais materiais apresentam área superficial maior que os polímeros orgânicos e são estruturalmente porosos. ${ }^{49}$ Entretanto, apesar da alta afinidade e seletividade, estes materiais exibem pobre acessibilidade do analito alvo ao sítio de ligação devido aos microporos que compõem o material. Desta forma, a cinética de adsorção/dessorção torna-se desfavorável devido à lenta transferência de massa do analito.

Devido a esta limitação, um novo processo de síntese para os IIPs tem sido proposto com uso de surfactantes..$^{50}$ Estes materiais preparados pelo processo sol-gel na presença de surfactantes recebem o nome de polímeros com dupla impressão, pois além da ligação do precursor funcional com o íon metálico de interesse, que caracteriza um sítio seletivo, o tamanho da cavidade seletiva pode ser controlado pela presença do surfactante, facilitando o acesso do analito ao sítio seletivo do IIP. ${ }^{50,51}$ A grande vantagem destes IIPs refere-se ao controle dos parâmetros estruturais dos polímeros, tais como volume 
e tamanho dos poros, conforme mostrado na Figura 5. Os canais gerados no polímero com diâmetro controlado permitem a rápida transferência de massa do analito ao sítio seletivo e, consequentemente, uma rápida cinética de adsorção/dessorção. Estes polímeros são classificados como materiais mesoporosos, pois os poros gerados apresentam diâmetros de 25 a 40 Å. Já materiais poliméricos com diâmetros variando de 1 a $3 \AA$ são considerados microporosos. ${ }^{50,51}$

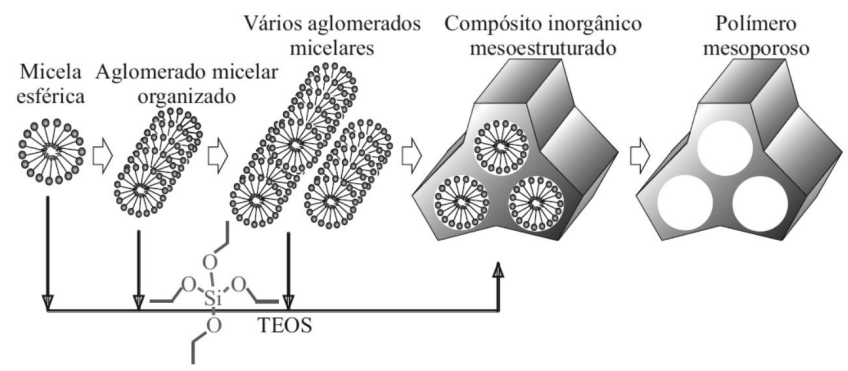

Figura 5. Representação esquemática da formação de polímero inorgânico mesoporoso. Adaptada da ref. 51

O primeiro trabalho referente ao uso dos IIPs preparados pelo processo sol-gel com dupla impressão foi publicado no ano de 2000. Dai e colaboradores sintetizaram um IIP seletivo a íons $\mathrm{Cu}^{2+}$ empregando TEOS, AAPTS e CTAB (brometo de cetiltrimetil amônio), como reticulante, precursor funcional e surfactante, respectivamente..$^{50}$ Mais tarde, os mesmos autores mostraram o desempenho dos IIP com dupla impressão para outros metais, $\mathrm{Ni}^{2+}$ e $\mathrm{Zn}^{2+}$, enfocando, basicamente, o uso de diferentes surfactantes e a caracterização do material por técnicas espectroscópicas. ${ }^{52}$ Outros trabalhos foram publicados visando a extração seletiva de $\mathrm{Cd}^{2+}, \mathrm{Hg}^{2+}$ e $\mathrm{Ni}^{2+}$ empregando os precursores funcionais 2-aminoetilamina-3-propiltrimetoxissilano e $N$-[3-(trimetoxi-silil)propil]etilenodiamine (TPED). ${ }^{53,54}$

Um aspecto que deve ser enfatizado refere-se às diferentes classes de precursores funcionais que podem ser empregadas visando à obtenção de polímeros com seletividade pronunciada. Precursores funcionais dotados de átomos de nitrogênio são preferencialmente empregados para impressão iônica de metais divalentes $\mathrm{Pb}^{2+}, \mathrm{Cd}^{2+}$, $\mathrm{Ni}^{2+}, \mathrm{Co}^{2+} \mathrm{eZn}^{2+}$, ao passo que o emprego de 3-mercaptopropiltrimetoxissilano, que possui o átomo de enxofre, permite realizar a impressão iônica de $\mathrm{Se}^{4+}, \mathrm{As}^{3+}, \mathrm{Hg}^{2+}$ e $\mathrm{Cd}^{2+} .{ }^{51}$ Neste ponto, nota-se também que, dependendo da seleção do precursor funcional, estudos de especiação química de espécies inorgânicas de arsênio e selênio também podem ser concebidos com o uso dos IIPs mesoporosos sintetizados via sol-gel. Apesar de promissor, não foram encontrados trabalhos publicados com IIPs capazes de efetuar a pré-concentração/determinação, em uma única etapa, de espécies inorgânicas de arsênio e selênio.

\section{POLÍMEROS HÍBRIDOS ORGÂNICOS-INORGÂNICOS IMPRESSOS COM ÍONS}

Materiais híbridos orgânico-inorgânicos são preparados pela combinação de componentes orgânicos e inorgânicos e constituem uma alternativa para a produção de novos materiais multifuncionais, com uma larga faixa de aplicações. São materiais de grande interesse em aplicações comerciais devido às suas propriedades mecânicas, ópticas e térmicas, que combinam a estabilidade térmica e química dos materiais cerâmicos com a processabilidade e a flexibilidade dos compostos e polímeros orgânicos. De um modo geral, existem diversas contestações com relação à definição de materiais híbridos, mas normalmente é feita de acordo com a natureza da interação entre os componentes orgânicos e inorgânicos. Tais materiais podem ser preparados de três modos: (1) pela incorporação apenas física dos constituintes; (2) através de ligações químicas entre os componentes orgânicos e inorgânicos e (3) baseada na combinação dos dois tipos de interações física e química descritos acima. ${ }^{55}$

Polímeros híbridos orgânico-inorgânicos impressos constituem uma classe relativamente nova de materiais que apresentam área superficial específica grande, tamanho de poros entre 2 e $15 \mathrm{~nm}$, sendo bem ordenados e com distribuição radial dos poros bem definida. A preparação de polímeros híbridos tem sido pouco empregada, mas o desenvolvimento de tais materiais apresenta grande interesse devido à combinação das propriedades orgânicas e inorgânicas e a criação de novos compostos. Polímeros híbridos apresentam algumas vantagens em relação aos polímeros orgânicos, tais como baixa densidade, boa estabilidade térmica e química, baixo custo de produção e flexibilidade na aplicação. ${ }^{56}$

O processo que tem sido amplamente utilizado na síntese de polímeros híbridos é o processo sol-gel para incorporação do íon na rede polimérica, usando TEOS como agente reticulante e moléculas orgânicas capazes de interagir com o íon de interesse. Cabe salientar que nesta abordagem de síntese o componente orgânico não é polimerizado, mas apenas ligado covalentemente à matriz inorgânica. Como exemplo, cita-se o trabalho de Makote e Dai que utilizaram ligantes baseados em diamina ligados covalentemente ao composto TEOS para reconhecimento seletivo de $\mathrm{Cu}^{2+}{ }^{57} \mathrm{Nesse}$ trabalho foi estudado o efeito do organossilano precursor na síntese do polímero híbrido, tendo sido avaliados o metiltrimetoxissilano e o feniltrimetoxissilano, que melhoraram muito a seletividade do polímero obtido. Tal fato foi explicado devido ao efeito da hidrofobicidade do grupo funcional $\mathrm{CH}_{3}-\mathrm{Si}$ e $\mathrm{C}_{6} \mathrm{H}_{5}-\mathrm{Si}$ destes copolímeros. Foi estudada também a utilização de diferentes volumes de co-solvente (tolueno) como um aditivo para modificar a hidrofobicidade da solução inicial, uma vez que os autores observaram que a seletividade do IIP está diretamente relacionada com este parâmetro. O estudo deste parâmetro alterou o valor de $k$ ' para os três copolímeros estudados, melhorando a seletividade. Esta diferença é atribuída à modificação da área superficial do polímero induzida pelo co-solvente na síntese sol-gel.

Polímeros híbridos orgânico-inorgânicos impressos também são definidos por alguns autores como polímeros inorgânicos, como apresentado na secção anterior. ${ }^{52,54}$ Assim sendo, quando polímeros impressos são preparados via processo sol-gel fazendo uso de precursores funcionais, tais como 3-mercaptopropiltrimetoxissilano ou 2-aminoetilamina-3-propiltrimetoxissilano e do agente reticulante TEOS, o polímero resultante pode ser definido como polímero orgânico-inorgânico impresso. Esta definição é aceita, tendo em vista que o grupo alcoóxido metálico do precursor funcional reage com o TEOS por meio de reações de condensação e policondensação, permitindo a formação da matriz polimérica. A fração orgânica dos precursores funcionais constituída por grupos amino $\left(-\mathrm{NH}_{2}\right)$ e mercapto (-SH) não é polimerizável, mas é responsável pela formação das cavidades seletivas.

É importante mencionar que os polímeros híbridos orgânico-inorgânicos impressos também podem ser preparados por meio do emprego de monômeros orgânicos e de alcoóxidos metálicos contendo grupos vinílicos, conhecidos com agentes de acoplamento. Na Figura 6 é apresentado um esquema de síntese de um polímero híbrido orgânico-inorgânico utilizando agente de acoplamento. ${ }^{56}$ Comparado aos demais polímeros híbridos, estes materiais permitem unir em um único material as propriedades orgânicas e inorgânicas. Desta forma, devido à possibilidade de combinar a enorme variabilidade funcional dos compostos orgânicos com a vantagem da estabilidade térmica e robustez dos substratos inorgânicos, tais materiais podem se figurar mais promissores no preparo de polímeros impressos com íons. Porém, o êxito na síntese destes polímeros depende da adequada adoção do solvente porogênico capaz de solubilizar os 
componentes inorgânico e orgânico a fim de produzir uma matriz polimérica homogênea. ${ }^{58}$

\section{SÍLICA GEL ORGANICAMENTE MODIFICADA E IM- PRESSA COM ÍONS}

Polímeros impressos preparados pelo método em bulk em sistema homogêneo são os mais utilizados em métodos de extração de íons metálicos, basicamente devido à sua simplicidade. No entanto, conforme já mencionado, estes polímeros exibem partículas com tamanhos irregulares, incompleta remoção do "template" e pobre acessibilidade dos analitos à cavidade seletiva. Problemas desta natureza podem ser contornados explorando a técnica de impressão bidimensional em superfície de suportes sólidos. Nestes materiais seletivos, o "template" pode ser completamente removido do adsorvente, tornando as cavidades seletivas presentes na superfície mais acessíveis à retenção do analito.

A sílica é um polímero inorgânico, representado por $\mathrm{SiO}_{2}$, sendo o átomo de silício coordenado por quatro átomos de oxigênio, e sua estrutura apresenta ligações siloxanos, $\mathrm{Si}-\mathrm{O}-\mathrm{Si}$, em seu interior e grupos de silanóis, $\mathrm{Si}-\mathrm{OH}$, em sua superfície. Estes últimos apresentam baixa acidez e uma fraca interação com íons metálicos. Este adsorvente apresenta baixa seletividade e, em solução básica, pode ocorrer hidrólise. Devido a estas características, a modificação da superfície da sílica gel (SG) tem sido uma alternativa para se obter um material adsorvente com maior seletividade e estabilidade química. ${ }^{10}$ Apesar de suas características, a sílica gel é considerada um suporte sólido ideal para impressão bidimensional, pois apresenta estabilidade mecânica à alta pressão, baixo intumescimento em diferentes solventes e pode ser comercializada com uma grande variedade de tamanho de partículas, formas e tamanho de poros. Os adsorventes com impressão bidimensional são preparados pelo método heterogêneo, que consiste em modificar organicamente a superfície da sílica gel com precursores organossilanos altamente reativos com a superfície da sílica e que contém usualmente átomos de nitrogênio ou enxofre. A interação destes átomos com o íon metálico é responsável pela formação da cavidade seletiva no adsorvente. ${ }^{59}$ A modificação da superfície da sílica gel com precursores organossilanos também confere, sobretudo, maior estabilidade química à sílica.

Além da sílica, existem ainda suportes sólidos orgânicos, tais como celulose e polímeros orgânicos, porém, estudos apontam que a sílica apresenta diversas características que favorecem a imobilização de reagentes analíticos sobre sua superfície, quando comparada aos polímeros orgânicos. ${ }^{11}$ Assim, devido às propriedades mencionadas, alguns trabalhos foram realizados utilizando a técnica de impressão de superfície em sílica gel organicamente modificada visando a quantificação de íons metálicos como $\mathrm{Pb}^{2+}, \mathrm{Ni}^{2+}, \mathrm{Fe}^{3+}, \mathrm{Cd}^{2+}, \mathrm{Co}^{2+} \mathrm{e} \mathrm{Cu}^{2+}{ }^{60}$

\section{SUPORTES SÓLIDOS GRAFTIZADOS E IMPRESSOS COM ÍONS}

A utilização de suportes sólidos aplicados às técnicas analíticas é bastante frequente na literatura desde os anos 50 e tem sua aplicação voltada basicamente para as técnicas de separação cromatográfica dos tipos líquido-sólido (adsorção), líquido-líquido (partição) e, principalmente, gás-líquido (partição), a qual precede o desenvolvimento das demais. Boscott ${ }^{61}$ descreveu a preparação de um suporte sólido através do tratamento de acetato de celulose com solvente e posterior aplicação deste material como fase estacionária em cromatografia de partição. Entretanto, vários tipos de materiais vêm sendo utilizados como suportes sólidos desde então. Entre estes, pode-se citar aos nanotubos de carbono, alumina, bentonita, grafite, zeolitas e principalmente a sílica gel (SG) ${ }^{62}$

É notável o desenvolvimento científico acerca destes suportes sólidos obtidos nos últimos anos quanto ao comportamento físico-químico, às características morfológicas, elucidação estrutural e também na diversidade de aplicações bem sucedidas. Observa-se também uma clara tendência no sentido de aumentar a complexidade estrutural destes materiais principalmente através de modificações químicas em sua superfície. Vários motivos justificam a alta popularidade deste recurso no meio científico, dependendo obviamente do campo de aplicação do produto final. Dentre eles tem-se como exemplo a modificação de propriedades físicas (solubilidade, reologia, ponto de fusão, dureza), ganho de funcionalidade através da modificação química da

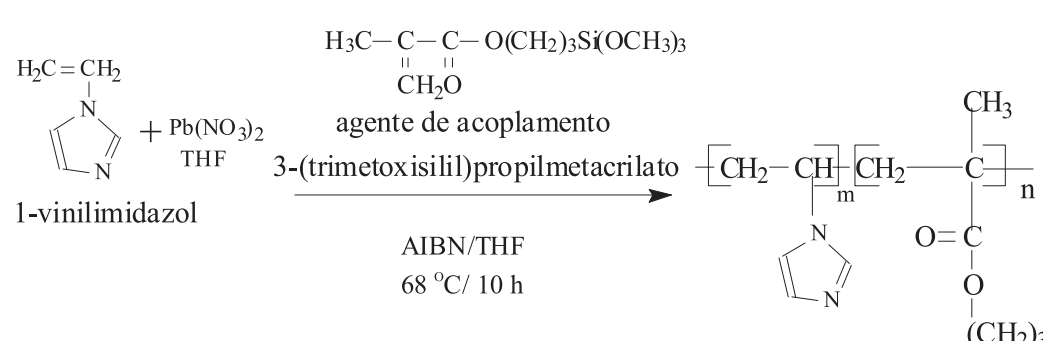

$\left(\mathrm{CH}_{2}\right)_{3} \mathrm{Si}\left(\mathrm{OCH}_{3}\right)_{3}$

\section{$\mathrm{TEOS} / \mathrm{HCl}$}

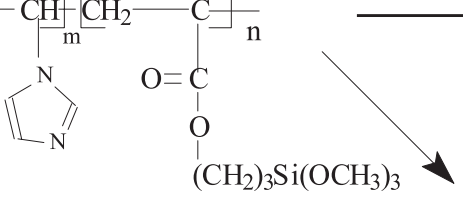

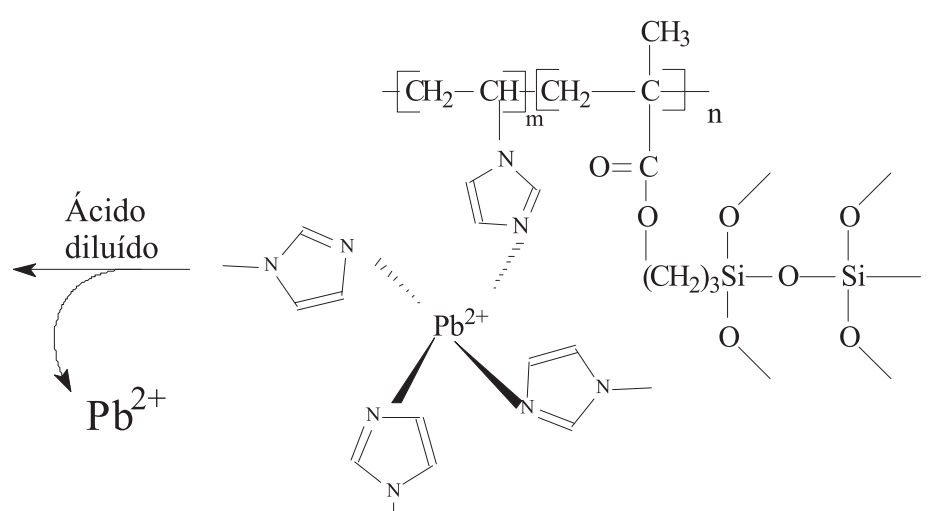

Figura 6. Representação esquemática da formação de polímero híbrido orgânico-inorgânico. Adaptada da ref. 56 
superfície com ancoragem de outros compostos (por exemplo, fases estacionárias quimicamente ligadas) e ganho de seletividade quando aplicado às técnicas analíticas (polímeros impressos imobilizados sobre suporte sólido) ${ }^{63}$ Assim, a síntese de polímeros ionicamente impressos associados à técnica de "grafting" (ou graftização) e sua aplicação em técnicas analíticas de alta seletividade ganha cada vez mais atenção.

Na literatura são encontrados trabalhos que utilizam a técnica de "grafting" desde a década de 1950, como no artigo publicado por Bridgeford que propõe a graftização de polímeros olefínicos sobre a superfície de celulose.$^{64}$ Nos anos subsequentes o enfoque dos estudos sobre esta técnica foi direcionado às variações de composição do material, ora alterando o tipo de suporte ou "backbone", ora alterando suas proporções, ou então às condições do meio de síntese, como pressão, temperatura ou fonte de energia. No entanto, a grande maioria destes trabalhos visou a alteração das características físicas do material. ${ }^{65} \mathrm{Na}$ segunda metade da década de 1960, Avny e colaboradores publicaram dois artigos descrevendo o sucesso na graftização de um polipeptídeo e uma unidade isolada de aminoácido sobre a superfície de acetato de celulose, respectivamente. ${ }^{66}$ Tal possibilidade amplia novos horizontes na utilização de materiais graftizados na química analítica em diferentes áreas, como por exemplo, os biosensores e técnicas de separação. ${ }^{67} \mathrm{O}$ alto desempenho obtido com esses materiais é justamente a grande vantagem oferecida, e que é devida ao alto grau de organização molecular, pois podem ser quimicamente manipulados de forma extremamente racional.

O termo "graftizado" origina-se da palavra inglesa "graft", e pode ser traduzida para o português como enxerto, expressando com grande precisão a disposição do arranjo molecular no material obtido quando se utiliza esta técnica na síntese de materiais nanoestruturados sobre suportes sólidos. Na prática, a técnica de "grafting" consiste em promover a imobilização através de interações químicas de determinado composto sobre um suporte sólido (principalmente a sílica), que em etapas subsequentes podem ser utilizados como precursores em reações químicas de síntese. Em se tratando de polímeros impressos nos quais se utiliza a técnica de "grafting" é necessário que o composto imobilizado atue como monômero funcional na etapa de síntese, na qual irá interagir com o "template" e, posteriormente, sofra ligações cruzadas para a formação do polímero.

Esta técnica possui basicamente duas etapas: (1) ancoragem através de ligações químicas covalentes de uma determinada molécula sobre um suporte sólido e (2) utilização da cadeia livre desta molécula como monômero funcional na etapa de polimerização e consequente impressão iônica. Entretanto, conforme a ordem de execução destas etapas pode-se classificar o processo de síntese do polímero impresso como sendo do tipo "grafting to", no qual primeiramente realiza-se o processo de impressão iônica, ligações cruzadas e polimerização e em seguida promove-se a fixação deste polímero impresso no suporte sólido, ou "grafting from", no qual a ordem é inversa à anterior, ou seja, primeiro fixa-se a cadeia contendo o monômero funcional na superfície do material sólido e posteriormente realiza-se a interação destes com o analito, reagentes de ligação cruzada e promove-se a polimerização. ${ }^{68}$ Apesar desta classificação, alguns autores consideram a graftização de uma cadeia polimérica, mesmo que ainda não haja impressão, como sendo "grafting to". ${ }^{69}$

A técnica de impressão iônica associada à de graftização apresenta como principal vantagem à possibilidade de se produzir materiais com estrutura organizada tanto de forma bidimensional em monocamada ("monolayer"), com a fixação do monômero no suporte sólido, quanto tridimensionalmente através da etapa de impressão. Logo, a distribuição dos sítios ativos do material melhora consideravelmente, diferentemente do produto obtido pela técnica de síntese em bulk, que por sua vez produz polímeros espessos, com número de sítios ativos relativamente baixos e com distribuição totalmente aleatória, ficando bastante dependente do grau de interação entre monômero e "template" antes da etapa de polimerização, o que definirá o posicionamento da cavidade impressa. ${ }^{70}$ Como já mencionado, a eficiência reduzida dos IIPs produzidos via bulk é comprovada através da determinação dos parâmetros cinéticos, que demonstram grande redução na transferência de massa entre o analito e o IIP.

Diante das vantagens apresentadas pela utilização da técnica de graftização sobre suporte sólido para a produção de polímeros ionicamente impressos, observa-se na literatura o empenho de pesquisadores na utilização e aperfeiçoamento desta técnica.

Gao e colaboradores descrevem em seu trabalho a síntese de materiais seletivos para $\mathrm{Cd}^{2+}$ e $\mathrm{Cu}^{2+}$ através da técnica de "grafting" utilizando em ambos o mesmo roteiro de síntese e reagentes. ${ }^{69}$ Para tanto, foi graftizada sobre a superfície de SG pelo método "grafting to" a polietilenoimina ( $\mathrm{PEI},\left[-\mathrm{NH}-\mathrm{CH}_{2}-\mathrm{CH}_{2}-\right]_{\mathrm{x}}$ ), um polímero solúvel em água de cadeia longa que atua como monômero funcional, tendo sua escolha relacionada ao grande número de átomos de nitrogênio (N) presentes nos grupos amina de sua cadeia polimérica, o que é indicativo de forte interação com íons metálicos. ${ }^{71}$

Outro ponto de destaque neste trabalho é a forma utilizada para imobilizar a PEI sobre a SG, através de acoplamento ("coupling"), na qual o $\gamma$-cloropropiltrimetoxissilano ( $\gamma$-CPTS) é utilizado como intermediário, de tal forma que a estrutura do material antes da impressão iônica seja a seguinte: SG- $\gamma$-CPTS-PEI. Em seguida, após lavagem deste material, o mesmo foi colocado em solução de $\mathrm{Cu}^{2+}$ para que ocorresse a quelação $\left(\mathrm{PEI}-\mathrm{Cu}^{2+}\right)$ e, posteriormente, filtrado e lavado até total esgotamento dos íons não adsorvidos pela PEI. Após esta etapa, o material encontra-se organizado bidimensionalmente e pronto para que seja procedida a impressão iônica e o consequente arranjo tridimensional, como apresentado na Figura 7a.

Realizou-se então esta reação em etanol absoluto, com aplicação de epicloridrina - 1-cloro-2,3-epóxipropano - $(\mathrm{ECH})$ como agente de ligação cruzada e hidróxido de sódio como catalisador. A ECH, apresentada na Figura 7b, é um reagente do grupo glicidil que possui grande capacidade de reagir com os hidrogênios ligados a átomos de nitrogênio da PEI na presença de $\mathrm{NaOH}$ e, consequentemente, promover a ligação rígida entre átomos de $\mathrm{N}$ de moléculas paralelas de PEI, apresentada na Figura 7, sendo capaz de estabilizar a estrutura de tal modo que o íon metálico pode ser removido permanecendo apenas a cavidade impressa, como apresentado na Figura $7 \mathrm{~d}$.

A eficiência do material impresso ficou comprovada pelo aumento na ordem de duas vezes na comparação do potencial de adsorção entre o material impresso (IIP-PEI/SiO$\left.)_{2}\right)$ e o não impresso $\left(\mathrm{PEI} / \mathrm{SiO}_{2}\right)$,

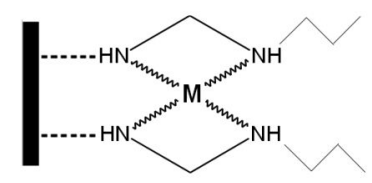

(a) (c)

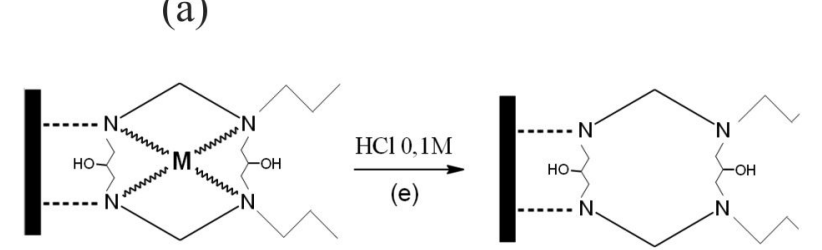

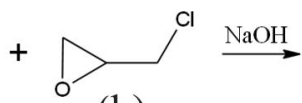

(b) (d)
Figura 7. Representação esquemática da síntese de um polímero ionicamente impresso pelo método do graftizado. (a) Interação entre o íon e os átomos de nitrogênio da cadeia de PEI; (b) reagente de ligação cruzada epicloridrina; (c) polímero impresso após realização das ligações cruzadas; (d) polímero impresso após remoção do íon "template”; (e) etapa de remoção do íon "template” com a utilização de solução ácida 
evidenciando a presença de cavidades seletivas. Outro fator importante é a seletividade do material para o íon o qual foi impresso na presença de concomitantes. Neste teste, o $\left(\mathrm{Cu}^{2+}\right) \mathrm{IIP}-\mathrm{PEI} / \mathrm{SiO}_{2}$ obteve um coeficiente de seletividade de 80,21 e 86,08 para os íons $\mathrm{Zn}^{2+} \mathrm{e} \mathrm{Ni}^{2+}$ respectivamente, enquanto o $\left(\mathrm{Cd}^{2+}\right) \mathrm{IIP}-\mathrm{PEI} / \mathrm{SiO}_{2}$ apresentou coeficientes de 71,05 e 88,22 para os íons $\mathrm{Cr}^{3+}$ e $\mathrm{Pb}^{2+}$ respectivamente. Os autores também destacam a facilidade de remoção dos íons adsorvidos, o que é uma vantagem na etapa de regeneração e reuso do material.

Embora tenha apresentado ótimo desempenho, o material desenvolvido por Gao e colaboradores deve obrigatoriamente utilizar a metodologia "grafting to", pois o monômero funcional utilizado (PEI) já se encontra em forma polimérica macromolecular, ou seja, apesar de apresentar-se em monocamada sobre o suporte não há como controlar o tamanho da cadeia da PEI que será precursora do IIP. ${ }^{69}$ Em outras palavras, o número de átomos de $\mathrm{N}$ disponíveis em uma cadeia de PEI é indefinido. Logo, as reações de ligação cruzada podem se propagar em direção ao meio reacional formando cavidades impressas com distribuição aleatória. A utilização desta metodologia também apresenta um revés importante que é a necessidade de utilização do iniciador radicalar livre (dissolvido) no meio reacional, o que é determinante na formação da cadeia polimérica, pois a reação de polimerização poderá iniciar-se em pontos distantes do suporte. Gasparrini e colaboradores e Shamsipur e colaboradores demonstram, no entanto, uma alternativa viável para contornar este obstáculo, que é a imobilização do iniciador na superfície do suporte. ${ }^{72}$ Desta forma, a reação de polimerização ocorrerá obrigatoriamente na superfície e adjacências do suporte sólido, sendo então classificada como "grafting from". Ambos os autores utilizam a aminopropil sílica gel ( $\mathrm{SG}-\mathrm{CH}_{2}-\mathrm{CH}_{2}-\mathrm{CH}_{2}-\mathrm{NH}_{2}$ ) como suporte para a imobilização do grupamento iniciador ácido 4,4'-azo-bis-(4-cianopentaenóico)(ACPA). Pode-se observar também que até o momento a maioria dos trabalhos desenvolvidos neste tema utiliza a SG como suporte, o que se justifica pelas vantagens apresentadas, como grande área superficial, alta resistência mecânica, boas características de transferência de massa e boa distribuição de tamanho de partículas, além de possuir composição química bastante uniforme em sua superfície $(\mathrm{Si}-\mathrm{OH}){ }^{73}$

É importante ressaltar que não há um aumento excessivo no custo e no grau de dificuldade de preparo de IIPs graftizados em relação aos IIPs sintetizados via métodos em bulk, pois basicamente há necessidade de se acrescentar o suporte sólido e um reagente intermediador para o processo de graftização. Entretanto, a realização do processo via "grafting" demanda maior planejamento da rota de síntese, o que necessariamente exige maior detalhamento dos processos químicos envolvidos, pois é sabido que neste caso, de acordo com a ordem que o processo de síntese é executado, considerando-se a adição de reagentes, aplicação de energia, ativação ou não do suporte sólido entre outros, o produto final será intrinsecamente diferente.

Outra observação importante esta relacionada aos reagentes que são usados, os quais são por muitas vezes os mesmos utilizados em outras técnicas de síntese de polímeros impressos tanto iônica como molecularmente. Como exemplo, destaca-se o reagente de ligação cruzada EGDMA, o monômero ácido metacrílico (AM) e o iniciador radicalar 4,4"-azobis(ácido cianopentanóico) (ACPA), evidenciando que a grande inovação apresentada por este tipo de material está no desenvolvimento racional da rota de síntese do ponto de vista químico, de forma a promover o aumento e melhor distribuição dos sítios ativos (cavidades) em diversos tipos de polímeros impressos.

\section{USO DE POLÍMEROS IMPRESSOS EM SENSORES QUÍMICOS E ELETROQUÍMICOS}

A determinação de íons metálicos usando polímeros impressos tem sido realizada por diferentes tipos de sensores com transdução óptica, potenciométrica e voltamétrica. ${ }^{74}$ Dentre eles, o método voltamétrico apresenta-se como o mais favorável para determinação de íons metálicos devido ao seu baixo custo, alta sensibilidade, facilidade de operação e possibilidade de ser portátil.

Visando a melhoria na sensibilidade e seletividade da determinação eletroquímica, eletrodos quimicamente modificados têm recebido um aumento de atenção nas ultimas décadas. $\mathrm{O}$ uso de polímeros impressos com íons como modificador destes sensores tem se apresentado como uma técnica promissora devido a seletividade pré-determinada. ${ }^{75,76}$

Dentre os sensores eletroquímicos, os eletrodos à base de pasta de carbono (EPC) apresentam algumas vantagens, tais como: simplicidade no preparo, facilidade de modificação e fácil regeneração da superfície sensora e corrente de fundo baixa para aplicações analíticas. Atualmente, algumas restrições ainda impedem o uso de tais eletrodos para uso em análise de traços, como o limite de detecção elevado, pequeno intervalo linear e/ou necessidade de um tempo de deposição relativamente grande. Assim, EPC modificados com IIP (EPC-IIP) se apresenta como uma técnica promissora e tem apresentado resultados promissores.

Para construção dos EPC-IIP, o polímero deve ser disperso e/ou dissolvido em um solvente apropriado e homogeneizado com grafite. Posteriormente, o solvente é evaporado seguido da adição de óleo mineral como aglutinante. A mistura é homogeneizada até a formação de uma pasta, a qual aplicada como uma fina camada (em torno de 2,0 $\mathrm{mm}$ de diâmetro e $3 \mathrm{~mm}$ de espessura) na cavidade de um eletrodo apropriado para tal finalidade, sendo o excesso devendo ser retirado com auxilio de um papel liso. ${ }^{77}$ Nesta técnica, a pasta pode ser reutilizada simplesmente retirando a pasta do eletrodo, de maneira a substituir o IIP que já tenha sido impresso.

Wang e colaboradores apresentaram a aplicabilidade de um EPC-IIP para determinação de $\mathrm{Cu}^{2+}$ por voltametria cíclica, onde é apresentada a simplicidade, rapidez, alta seletividade, aplicabilidade, baixo custo, facilidade de uso e sensibilidade adequada para níveis baixos de $\mathrm{Cu}^{2+}$ em soluções aquosas, apresentando limite de detecção de $2,3 \times 10^{-8} \mathrm{~mol} \mathrm{~L}^{-1} .{ }^{77}$ Para isso, utilizou-se a polimerização térmica com os monômeros 4-VP e acrilamida (AC), TRIM como agente de ligação cruzada e AIBN como iniciador radicalar. Alizadeh e Amjadi recentemente publicaram trabalhos envolvendo a aplicação de IIPs em sensores eletroquímicos empregando-se voltametria e potenciometria para determinação de $\mathrm{Pb}^{2+} \mathrm{e} \mathrm{Cd}^{2+}$ em diferentes amostras de água. ${ }^{78,79}$ Para determinação de $\mathrm{Hg}^{2+}$ via sensor voltamétrico, um novo procedimento foi proposto sem o uso do agente reticulante, neste caso, a vinilpiridina foi utilizada como monômero e agente reticulante. ${ }^{80}$ Desta maneira, os íons $\mathrm{Hg}^{2+}$ interagem somente com a vinilpiridina, ambos dissolvidos em dimetilsulfóxido na presença do iniciador radicalar, o que facilita o estudo da reação e possibilita uma melhor otimização.

Como alternativa aos EPC-IIP, a utilização de IIP pode ser feita pela formação de um filme na superfície de um eletrodo sólido. Neste caso, o polímero é sintetizado diretamente na superfície, por exemplo, de um eletrodo de carbono vítreo. Quando o filme é polimerizado na superfície, produz sítios impressos seletivos ao íon molde, combinado com a condutividade do substrato, facilita a transferência eletrônica através do eletrodo. Nanopartículas tem sido amplamente utilizadas juntamente com os IIPs, por exemplo, ouro e nanotubos de carbono. Sua utilização é indicada para reforçar a condutividade no material substrato, produzindo material com estrutura core-shell impresso com íons. Fu e colaboradores eletropolimerizaram um filme de poli(2-mercaptobenzotiazol) (PMBT) com $\mathrm{Hg}^{2+}$ na superfície de um eletrodo de carbono vítreo modificado com material nanohíbrido de partículas de ouro e nanotubo de carbono. ${ }^{81}$ Neste caso, o polímero é produzido in situ na superfície do eletrodo (eletropolimerizado). 
O eletrodo funcionalizado exibiu maior capacidade de ligação com rápida cinética de ligação, maior seletividade para o $\mathrm{Hg}^{2+}$ que para os interferentes, boa repetibilidade e se mostrou potencialmente viável para experimentos on-line e detecção de $\mathrm{Hg}^{2+}$ no meio ambiente.

Sensores ópticos (optodos) têm sido utilizados para determinação de muitos íons. Tais sensores, em particular, se baseiam nas propriedades luminescentes dos materiais ou de suas reações. Desta maneira, durante estudos da coordenação entre certos monômeros e analitos, foi observada a possibilidade de aplicação dos IIPs em sensores ópticos, o que possibilita vantagens em relação a outros tipos de transdutores, como os eletroquímicos, pois permitem medidas diretas, mais rápidas e sensíveis. Um tipo de aplicação do uso de IIPs na confecção de sensores ópticos foi reportado por Murray e colaboradores explorando a reação de complexação entre o metil-3,5-divinilbenzoato (DVMB)

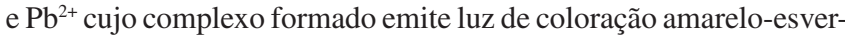
deado. ${ }^{76}$ Outro exemplo que diz respeito à determinação de $\mathrm{Hg}^{2+}$ se utiliza a 4-vinilpiridina como monômero funcional, EDGMA como agente reticulante e a característica fluorescente do grupo carbazol, utilizando-se o monômero 9-vinilcarbazol ( $\mathrm{VCz})$, para construção do sensor óptico. ${ }^{82}$ Para quantificação de zinco e $\mathrm{Cd}^{2+}$ foi utilizada a 8-hidroxiquinolina com o monômero funcional 3-aminopropiltrietoxissilano de maneira a produzir um monômero funcional fluorescente e o TEOS como agente reticulante. ${ }^{83}$ Para determinação de $\mathrm{Pb}^{2+}$ também foi utilizado o $\mathrm{VCz}$, entretanto utilizou-se o ácido metacrílico como monômero funcional. ${ }^{84}$ Para quantificação de alumínio se utilizou o complexo quelato $\mathrm{Al}^{3+}-3,5,7,2^{\prime}, 4^{\prime}$-pentahidroxiflavona como molde, visto que este produz um complexo fluorescente com íons metálicos em solução, ácido metacrílico como monômero funcional, EDGMA como agente reticulante, AIBN como iniciador e tolueno, diclorometano ou acetonitrila como solventes porogênicos. ${ }^{85}$ Neste trabalho, verificou-se que solventes porogênicos apolares, como o tolueno, fornecem melhores resultados. Finalmente, $\mathrm{Cu}^{2+}$ pode ser quantificado em amostras aquosas resultando em um sensor com grande seletividade e que pode ser regenerado mais de 50 vezes sem significante perda nas propriedades luminescentes, o que comprovou a viabilidade econômica do polímero. ${ }^{86}$

\section{CONSIDERAÇÕES FINAIS}

A constante evolução da ciência e a crescente demanda por novas tecnologias têm despertado o interesse de alguns pesquisadores para o desenvolvimento de metodologias e técnicas inovadoras. Parte deste desenvolvimento diz respeito à possibilidade de detecção e quantificação de analitos em níveis traços em diferentes tipos de matriz com seletividade pronunciada mesmo na presença de grandes quantidades de interferentes. O processo de impressão química com íons é uma tecnologia emergente para a produção de materiais poliméricos altamente seletivos. De maneira geral, o processo de síntese dos IIPs é considerado simples, rápido, de baixo custo, e apresenta possibilidade de várias rotas sintéticas e aplicações. Nas Tabelas $1 \mathrm{e}$ 2 são apresentados, de maneira geral, os procedimentos de síntese, materiais de partida e as propriedades dos IIPs.

Tabela 1. Resumo dos procedimentos de síntese, materiais de partida e material resultante dos polímeros impressos com íons

\begin{tabular}{|c|c|c|c|c|c|}
\hline Íon & Polímero & $\begin{array}{l}\text { Principais materiais de partida } \\
\text { empregados }\end{array}$ & Principais características do procedimento de síntese & $\begin{array}{l}\text { Material } \\
\text { resultante }\end{array}$ & REF. \\
\hline \multirow{10}{*}{$\mathrm{Cu}^{2+}$} & \multirow{5}{*}{ Orgânico } & $\begin{array}{l}\text { Etilenoimina; vinilpiridina; } \\
\text { Álcool polivinílico e poliacrilato. }\end{array}$ & $\begin{array}{l}\text { Formação de um complexo reticulado entre cadeia polimérica e o } \\
\text { íon que após a reação é removido pelo tratamento da resina com } \\
\text { solução ácida. }\end{array}$ & \multirow{2}{*}{ Resina } & 13,15 \\
\hline & & $\begin{array}{l}\text { 1-vinilimidazol; 1-vinil-2- } \\
\text { pirolidona. }\end{array}$ & $\begin{array}{l}\text { Formação de um complexo metal-1-vinilimidazol reticulado com } \\
\text { 1-vinil-2-pirolidona por irradiação com raios gama e remoção do } \\
\text { metal pelo tratamento da resina com solução ácida. }\end{array}$ & & 18 \\
\hline & & $\begin{array}{l}\text { poli(glicidilmetacrilato); } \\
\text { polietilenoimina; nitrato cúprico } \\
\text { trihidrato; epicloroidrina, } \\
\text { polipropileno. }\end{array}$ & $\begin{array}{l}\text { Polimerização por impressão superficial, onde } \\
\text { poli(glicidilmetacrilato) é enxertado em uma fibra de polipropileno } \\
\text { que reage com uma solução do íon, que posteriormente é extraído } \\
\text { com solução ácida. }\end{array}$ & Fibra & 26 \\
\hline & & $\begin{array}{l}\text { Ácido Metacrílico; Acetato, } \\
\text { Picolinamida;4-Vinilpiridina, } \\
\text { EGDMA, AIBN }\end{array}$ & $\begin{array}{l}\text { Polimerização por bulk, onde o complexo Cu-Picolinamida é dis- } \\
\text { solvido juntamente com o monômero, agente reticulante e iniciador } \\
\text { radicalar, sob polimerização térmica e atmosfera de nitrogênio. }\end{array}$ & Particulado & 40 \\
\hline & & Álcool polivinílico; água. & $\begin{array}{l}\text { Polimerização por dispersão, onde complexo formado é disperso em } \\
\text { água / álcool polivinílico, agitado magneticamente, polimerizado } \\
\text { por aquecimento em banho térmico ou raio gama }{ }^{24} \text { sob atmosfera } \\
\text { de nitrogênio. }\end{array}$ & Gioroesfer & 9,24 \\
\hline & Sílica Gel & 3-aminopropiltrimetoxissilano & $\begin{array}{l}\text { Ativação da sílica com utilização de ácido hidroclorídrico. Solução } \\
\text { do íon foi dissolvida em metanol com posterior adição de } 3 \text {-amino- } \\
\text { propiltrimetoxissilano e da sílica ativada. A remoção do template é } \\
\text { realizada utilizando-se solução ácida. }\end{array}$ & Cia & 60 \\
\hline & Inorgânico & TEOS; AAPTS e CTAB. & $\begin{array}{l}\text { Polimerização via processo sol-gel e uso de surfactantes (dupla } \\
\text { impressão). }\end{array}$ & Sílica & 50,52 \\
\hline & $\begin{array}{l}\text { Suportes sóli- } \\
\text { dos graftizados }\end{array}$ & $\begin{array}{l}\text { Polietilenoimina, } \\
\text { epichlorohydrin, } \gamma \text { - } \\
\text { cloropropiltrimetoxissilano }\end{array}$ & $\begin{array}{l}\text { Graftizado sobre a superfície de SG, onde a sílica é primeiramente } \\
\text { ativada usando solução ácida e depois misturada com uma solução } \\
\text { do íon. Para criação da cavidade seletiva o íon é extraído utilizando- } \\
\text {-se uma solução ácida } 0,1 \mathrm{~mol} \mathrm{~L}^{-1}\end{array}$ & Particulado & 69,71 \\
\hline & Sensores & $\begin{array}{l}\text { 4-[(E)-2-(4'-methyl-2,2'- } \\
\text { bipyridin-4-yl)vinyl]phenyl } \\
\text { methacrylate }\end{array}$ & $\begin{array}{l}\text { Polimerização por bulk utilizando-se monômero funcional fluores- } \\
\text { cente e aplicado sobre a superfície de um detector de fluorescência. }\end{array}$ & & 86 \\
\hline & & $\begin{array}{l}\text { 4-VP; AC; TRIM e AIBN } \\
\text { Trimetilolpropanotrimetacrilato. }\end{array}$ & $\begin{array}{l}\text { Polimerização por bulk e homogeneizado em pasta de carbono para } \\
\text { construção do eletrodo. }\end{array}$ & Pasta & 77 \\
\hline
\end{tabular}


Tabela 1. continuação

\begin{tabular}{|c|c|c|c|c|c|}
\hline Íon & Polímero & $\begin{array}{l}\text { Principais materiais de partida } \\
\text { empregados }\end{array}$ & Principais características do procedimento de síntese & $\begin{array}{l}\text { Material } \\
\text { resultante }\end{array}$ & REF. \\
\hline \multirow[t]{4}{*}{$\mathrm{Fe}^{3+}$} & Sílica gel & 3-aminopropiltrimetoxissilano & $\begin{array}{l}\text { Ativação da sílica com utilização de ácido hidroclorídrico. Solução } \\
\text { do íon foi dissolvida em metanol, com posterior adição de 3-ami- } \\
\text { nopropiltrimetoxissilano e da sílica ativada. A remoção do template } \\
\text { é realizada utilizando-se solução ácida. }\end{array}$ & Microesfera & 60 \\
\hline & Orgânico & \multirow{2}{*}{$\begin{array}{l}\text { Etilenoimina; vinilpiridina; } \\
\text { Álcool polivinílico e poliacrilato. }\end{array}$} & $\begin{array}{l}\text { Formação de um complexo reticulado entre cadeia polimérica e o } \\
\text { ín que após a reação é removido pelo tratamento da resina com } \\
\text { solução ácida. }\end{array}$ & \multirow{3}{*}{ Resina } & 13,15 \\
\hline & \multirow{3}{*}{ Orgânico } & & $\begin{array}{l}\text { Formação de um complexo reticulado entre cadeia polimérica e o } \\
\text { íon que após a reação é removido pelo tratamento da resina com } \\
\text { solução ácida. }\end{array}$ & & 13,15 \\
\hline & & $\begin{array}{l}\text { 1-vinilimidazol; 1-vinil-2- } \\
\text { pirolidona. }\end{array}$ & $\begin{array}{l}\text { Formação de um complexo metal-1-vinilimidazol reticulado com } \\
\text { 1-vinil-2-pirolidona por irradiação com raios gama e remoção do } \\
\text { metal pelo tratamento da resina com solução ácida. }\end{array}$ & & 18 \\
\hline $\mathrm{Co}^{2+}$ & & Álcool polivinílico; água. & $\begin{array}{l}\text { Polimerização por dispersão, onde complexo formado é disperso em } \\
\text { água / álcool polivinílico, agitado magneticamente, polimerizado } \\
\text { por radiação gama sob atmosfera de nitrogênio. }\end{array}$ & Microesferas & 24 \\
\hline
\end{tabular}
por radiação gama sob atmosfera de nitrogênio.

Ativação da sílica com utilização de ácido hidroclorídrico. Solução

Sílica gel 3-aminopropiltrimetoxissilano do íon foi dissolvida em metanol, com posterior adição de 3-aminopropiltrimetoxissilano e da sílica ativada. A remoção do template é realizada utilizando-se solução ácida.

Etilenoimina; vinilpiridina; Álcool polivinílico e poliacrilato.

Formação de um complexo reticulado entre cadeia polimérica e o íon que após a reação é removido pelo tratamento da resina com solução ácida.

1,12-Dodecanodiol- $O, O$ ' - ácido

Orgânico difenilfosfórico.

Polimerização por impressão superficial utilizando irradiação gama.

Resina

1,12-Dodecanodiol- $O, O^{\prime}$

ácido difenilfosfórico com

DVB, Ácido L-glutâmico

Polimerização por impressão superficial utilizando água/óleo.

dioleylesterribitol

\section{Inorgânicos TEOS; AAPTS e CTAB.}

Etilenoimina; vinilpiridina; Álcool polivinílico e poliacrilato.

Álcool polivinílico; água.

Orgânico

1-vinilimidazol; 1-vinil-2pirolidona.

Histidina hidratada metacrílica e EGDMA

$\mathrm{Ni}^{2+}$

1,12-Dodecanodiol- $O, O^{\prime}$ - ácido difenilfosfórico.

\begin{tabular}{ll}
\hline Inorgânico & TEOS; AAPTS e CTAB. \\
Híbrido & $\begin{array}{l}\text { 2-aminoetil-3- } \\
\text { aminobutilmetildimetoxissilano } \\
\text { e tetraetoxissilano }\end{array}$ \\
\hline
\end{tabular}

Sílica gel 3-aminopropiltrimetoxissilano

Etilenoimina; vinilpiridina;

Orgânico

$\mathrm{Hg}^{2+}$
Polimerização via processo sol-gel e uso de surfactantes (dupla impressão).

Formação de um complexo reticulado entre cadeia polimérica e o íon que após a reação é removido pelo tratamento da resina com solução ácida.

Polimerização por dispersão, onde complexo formado é disperso em água / álcool polivinílico, agitado magneticamente, polimerizado por radiação gama sob atmosfera de nitrogênio.

Formação de um complexo metal-1-vinilimidazol reticulado com 1-vinil-2-pirolidona por irradiação com raios gama e remoção do metal pelo tratamento da resina com solução ácida.

Polimerizado por dispersão, onde o complexo iônico foi polimerizado com um agente reticulante para obtenção do polímero.

Polimerização por impressão superficial utilizando irradiação gama.

Polimerização via processo sol-gel e uso de surfactantes (dupla impressão).

Primeiramente é formado um complexo iônico, este é diluído posteriormente em um precursor inorgânico e agitado com aquecimento. O íon é retirado utilizando-se solução ácida.

Ativação da sílica com utilização de ácido hidroclorídrico. Solução do íon foi dissolvida em metanol, com posterior adição de 3-aminopropiltrimetoxissilano e da sílica ativada. A remoção do template é realizada utilizando-se solução ácida.

Formação de um complexo reticulado entre cadeia polimérica e o íon que após a reação é removido pelo tratamento da resina com solução ácida.

Polimerização por bulk, onde o íon foi removido utilizando-se uma solução ácida.

vinilpiridina EDGMA e AIBN

Uso de surfactantes (dupla impressão) e criação da cavidade seletiva utilizando-se solução ácida para remoção do íon.
Membrana

44

Microesferas

24

Resina

18

Particulado

8

Resina

25

Sílica

50,52

Particulado

54

.


Tabela 2. Resumo das propriedades e desempenho dos polímeros impressos com íons

\begin{tabular}{|c|c|}
\hline $\begin{array}{l}\text { Tipos de } \\
\text { polímeros }\end{array}$ & Síntese/Aplicações Analíticas \\
\hline $\begin{array}{l}\text { Polímeros } \\
\text { orgânicos }\end{array}$ & $\begin{array}{l}\text { São os mais utilizados atualmente e com síntese mais simples, } \\
\text { portanto os mais reportados. Podem ser preparados a partir de } \\
\text { diferentes abordagens de síntese, incluindo polimerização em bulk, } \\
\text { precipitação e suspensão. Podem ser aplicados no desenvolvim- } \\
\text { ento de métodos de pré-concentração em fase sólida e de sensores } \\
\text { eletroquímicos. }\end{array}$ \\
\hline
\end{tabular}
eletroquímicos.

\section{Características/Desempenho}

Polímeros rígidos, apresentam boa estabilidade térmica, química e mecânica. O desempenho dependerá do tipo de síntese adotada. Polímeros preparados via reação em meio homogêneo (bulk) possuem partículas não uniformes devido o processo de moagem e possuem área superficial relativamente pequena. Polímeros preparados via método de suspensão e precipitação originam partículas com tamanhos mais uniformes. Os polímeros orgânicos geralmente apresentam capacidade de retenção em torno de 70 a $100 \%$.

Basicamente apresentam as mesmas aplicações dos polímeros orgânicos. São preparados via processo sol-gel com emprego de Polímeros precursores organossilanos. Majoritariamente tem sido utilizado inorgânicos em aplicações envolvendo métodos de pré-concentração de íons acoplados com técnicas espectroanalíticas

Polímeros

híbridos

orgânicos-

inorgânicos
São polímeros que estão em estágio incipiente em relação à aplicação como fase extratora de íons metálicos, mas podem ser utilizados para o mesmo fim.

Apresentam área superficial maior que os polímeros orgânicos, maior estabilidade térmica e podem ser estruturalmente porosos fazendo uso de moléculas surfactantes como templates.

Várias possibilidades de síntese. Em relação aos polímeros orgânicos apresentam vantagens como baixa densidade e boa estabilidade térmica e química. Apresentam área superficial específica alta, sendo bem ordenados e com distribuição radial dos poros bem definida, principalmente pelo processo sol-gel, tal como se observa nos polímeros inorgânicos. Porém, nos polímeros híbridos, é possível associar o efeito dos monômeros orgânicos com os precursores inorgânicos visando obter maior seletividade ao polímero.

Apresentam maior taxa de adsorção tendo em vista que os sítios seletivos estão presentes na superfície, estabilidade mecânica à alta pressão, baixo intumescimento em diferentes solventes, e possibilita a comercialização com uma grande variedade de tamanho de partículas, formas e tamanho de poros.

nossilano e explora a técnica de impressão bidimensional. Este organicamente tipo de material impresso também tem sua aplicação voltada para modificada o desenvolvimento de métodos de pré-concentração em fase sólida.

Técnica baseada na reação de polimerização sobre suporte sólido,

Suportes sólidos graftizados com objetivo de obter partículas uniformes quimicamente impressas. Aplicações como fase extratora de íons metálicos e fase estacionária para cromatografia líquida de alta eficiência.
O material polimérico resultante demanda maior planejamento da rota de síntese, em comparação com os demais tipos de polímeros. Porém, obtêm-se partículas com tamanhos mais uniformes, maior taxa de adsorção dos íons metálicos e altos coeficientes de seletividade.
Além disto, os IIPs são quimicamente resistentes podendo ser reutilizáveis. Os IIPs sintetizados via ligação não covalente com o íon metálico, bem como pela técnica de impressão química bidimensional em superfície de suportes sólidos são os mais comuns, mas polímeros impressos híbridos mesoporosos e suportes sólidos graftizados e impressos com íons também podem ser concebidos. Dentre as aplicações dos IIPs, os métodos analíticos baseados em extração em fase sólida de íons metálicos associados com técnicas de emissão e absorção atômica ainda são majoritários, mas é crescente o número de estudos envolvendo o preparo de sensores eletroquímicos e principalmente ópticos. Como perspectiva futura cita-se a necessidade de obtenção de novos polímeros, em especiais aqueles hierarquicamente impressos, visando melhorar a cinética de transferência do analito para o sítio seletivo e garantir a remoção completa do "template" da cavidade dos IIPs. Ainda, o desenvolvimento de métodos analíticos de especiação química fazendo uso de IIPs e o acoplamento com técnicas pouco seletivas são ramos de aplicação da tecnologia de impressão química que ainda devem ser exploradas.

\section{AGRADECIMENTOS}

Os autores agradecem à Fundação Araucária do Paraná, CNPq (Conselho Nacional de Desenvolvimento Científico e Tecnológico processos 471912/2011-5, 471655/2011-2, 308580/2010-9), CAPES (Coordenação de Aperfeiçoamento de Pessoal de Nível Superior), FAPESP (Fundação de Amparo a Pesquisa do Estado de São Paulo) e INCT (Instituto Nacional de Ciência e Tecnologia) de Bioanalítica (processo n 57.3672/2008-3) pelos auxílios financeiros e/ou bolsas concedidas.

\section{REFERÊNCIAS}

1. He, L.; Toh, C. S.; Anal. Chim. Acta 2006, 556, 1.

2. Namiesnik, J.; Crit. Rev. Anal. Chem. 2000, 30, 221.

3. Haupt, K.; Anal. Chem. 2003, 75, 376A; Ye, L.; Mosbach, K.; J. Inclusion Phenom. Macrocyclic Chem. 2001, 41, 107.

4. Sellergren, B.; TrAC, Trends Anal. Chem. 1997, 16, 310.

5. Garcia-Viloca, M.; Gao, J.; Karplus, M.; Truhlar, D. G.; Science 2004, 303, 186.

6. Sartori, L.R.; Santos, W.J.; Kubota, L.T.; Segatelli, M.G.; Tarley, C.R.T.; Mater. Sci. Eng., C 2011, 31, 114.

7. Masque, N.; Marce, R. M.; Borrull, F.; TrAC, Trends Anal. Chem. 1998, 17, 6; Mayes, A. G.; Mosbach, K.; TrAC, Trends Anal. Chem. 1997, 16, 321; Santos, W.J.R.; Lima, P.R.; Tarley, C.R.T.; Höehr, N.F.; Kubota, L.T.; Anal. Chim. Acta 2009, 631, 170.

8. Ersoz, A.; Say, R.; Denizli, A.; Anal. Chim. Acta 2004, 502, 91.

9. Say, R.; Birlik, E.; Ersoz, A.; Yilmaz, F.; Gedikbey, T.; Denizli, A.; Anal. Chim. Acta 2003, 480, 251.

10. Tarley, C. R. T.; Sotomayor, M. D. P. T.; Kubota, L. T.; Quim. Nova 2005, 28, 1076; Segatelli, M.G.; Santos, V.S.; Presotto, A.B.T.; Yoshida, I.V.P.; Tarley, C.R.T.; React. Funct. Polym. 2010, 70, 325.

11. Rao, T. P.; Ramakrishnan, K.; Daniel, S.; Anal. Chim. Acta 2006, 578 , 105.

12. Daniel, S.; Rao, P. P.; Rao, T. P.; Anal. Chim. Acta 2005, 536, 197.

13. Nishide, H.; Deguchi, J.; Tsuchida, E.; Chem. Lett. 1976, 5, 169.

14. h t t p : / / a p p s.webofknowledge.com/U A _ G e neral $\mathrm{Search}$ in put.do? product=UA\& s e a r ch mode $=$ GeneralSearch $\&$ SID $=3$ EGnefBpGmpNcegF5e6\&preferencesSa ved=, acessada em Janeiro 2013. 
15. Nishide, H.; Tsuchida, E.; Macromol. Chem. Phys. 1976, 177, 2295; Nishide, H.; Deguchi, J.; Tsuchida, E.; J. Polym. Sci., Part A: Polym. Chem. 1977, 15, 3023.

16. Efendiev, A. A.; Kabanov, V. A.; Pure Appl. Chem. 1982, 54, 2077.

17. Ohga, K.; Kurauchi, Y.; Yanase, H.; Bull. Chem. Soc. Jpn. 1987, 60, 444.

18. Kato, M.; Nishide, H.; Tsuchida, E.; Sasaki, T.; J. Polym. Sci., Part A: Polym. Chem. 1981, 19, 1803.

19. Garcia, R.; Pinel, C.; Madic, C.; Lemaire, M.; Tetrahedron Lett. 1998, 39, 8651 .

20. Garcia, R.; Vigneau, O.; Pinel, C.; Lemaire, M.; Sep. Sci. Technol. 2002, 37, 2839.

21. Fasihi, J.; Alahyari, S. A.; Shamsipur, M.; Sharghi, H.; Charkhi, A.; React. Funct. Polym. 2011, 71, 803.

22. Say, R.; Ersoz, A.; Turk, H.; Denizli, A.; Sep. Purif. Technol. 2004, 40, 9.

23. Kido, H.; Tsukagoshi, K.; Maeda, M.; Takagi, M.; Miyajima, T.; Anal. Sci. 1992, 8, 749 .

24. Yu, K. Y.; Tsukagoshi, K.; Maeda, M.; Takagi, M.; Anal. Sci. 1992, 8, 701; Tsukagoshi, K.; Yu, K.; Maeda, M.; Takagi, M.; Kobunshi Ronbunshu 1993, 50, 455; Tsukagoshi, K.; Yu, K.Y.; Maeda, M.; Takagi, M.; Bull. Chem. Soc. Jpn. 1993, 66, 114; Tsukagoshi, K.; Yu, K.Y.; Maeda, M.; Takagi, M.; Miyajima, T.; Bull. Chem. Soc. Jpn. 1995, 68, 3095; Okubo, M.; Kanaida, K.; Matsumoto, T.; J. Appl. Polym. Sci. 1987, 33, 1511; Yokoi, H.; Kawata, S.; Iwaizumi, M.; J. Am. Chem. Soc. 1986, 108,3361

25. Yoshida, M.; Uezu, K.; Goto, M.; Nakashio, F.; J. Chem. Eng. Jpn. 1996, $29,174$.

26. Li, T. Y.; Wu, L.; Chen, S. X.; Li, H. C.; Xu, X. Z.; Macromol. Chem. Phys. 2011, 212, 2166.

27. Uezu, K.; Nakamura, H.; Goto, M.; Murata, M.; Maeda, M.; Takagi, M.; Nakashio, F.; J. Chem. Eng. Jpn. 1994, 27, 436; Uezu, K.; Nakamura, H.; Kanno, J.; Sugo, T.; Goto, M.; Nakashio, F.; Macromolecules 1997, 30, 3888; Yoshida, M.; Uezu, K.; Goto, M.; Furusaki, S.; Macromolecules 1999, 32, 1237; Uezu, K.; Nakamura, H.; Goto, M.; Nakashio, F.; Furusaki, S.; J. Chem. Eng. Jpn. 1999, 32, 262; Uezu, K.; Tazume, N.; Yoshida, M.; Goto, M.; Furusaki, S.; Kagaku Kogaku Ronbunshu 2001, 27, 753. Yoshida, M.; Uezu, K.; Goto, M.; Furusaki, S.; J. Appl. Polym. Sci. 1999, 73, 1223; Yoshida, M.; Uezu, K.; Nakashio, F.; Goto, M.; J. Polym. Sci., Part A: Polym. Chem. 1998, 36, 2727.

28. Liu, Y.; Liu, Z.C.; Gao, J.; Dai, J.D.; Han, J.A.; Wang, Y.; Xie, J.M.; Yan, Y.S.; J. Hazard. Mater. 2011, 186, 197.

29. Otero-Romani, J.; Moreda-Pineiro, A.; Bermejo-Barrera, P.; MartinEsteban, A.; Talanta 2009, 79, 723.

30. Preetha, C.R.; Joseph, M.G.; Rao, T.P.; Venkateswaran, G.; Environ. Sci. Technol. 2006, 40, 3070.

31. Kala, R.; Gladis, J.M.; Rao, T.P.; Anal. Chim. Acta 2004, 518, 143; Biju, V.M.; Gladis, J.M.; Rao, T.P.; Anal. Chim. Acta 2003, 478, 43; Krishna, P.G.; Gladis, J.M.; Rao, T.P.; Naidu, G.R.; J. Mol. Recognit. 2005, 18, 109.

32. Kala, R.; Gladis, J.M.; Rao, T.P.; US. pat.PCT/INO3/00427, 2003

33. Kala, R.; Biju, V. M.; Rao, T. P.; Anal. Chim. Acta 2005, 549, 51.

34. Gladis, J. M.; Rao, T. P.; Anal. Lett. 2003, 36, 2107.

35. Gladis, J. M.; Rao, T. P.; Microchim. Acta 2004, 146, 251.

36. Metilda, P.; Joseph, M.G.; Venkateswaran, G.; Rao, T. P.; Anal. Chim. Acta 2007, 587, 263.

37. Daniel, S.; Joseph, M.G.; Rao, T. P.; Anal. Chim. Acta 2003, 488, 173.

38. Liu, Y. W.; Chang, X. J.; Yang, D.; Guo, Y.; Meng, S. M.; Anal. Chim. Acta 2005, 538, 85.

39. Liu, Y. W.; Chang, X. J.; Wang, S.; Guo, Y.; Din, B. J.; Meng, S. M.; Anal. Chim. Acta 2004, 519, 173.

40. Wu, L. Q.; Li, Y. Z.; Anal. Chim. Acta 2003, 482, 175.

41. Ulbricht, M.; J. Chromatogr. B 2004, 804, 113

42. Faizal, C. K. M.; Kobayashi, T.; J. Appl. Sci. 2011, 11, 2411.
43. Kimaro, A.; Kelly, L. A.; Murray, G. M.; Chem. Commun. 2001, 14 , 1282.

44. Araki, K.; Maruyama, T.; Kamiya, N.; Goto, M.; J. Chromatogr. B 2005, 818,141

45. Murray, G. M.; US pat. 6, 738, 323, 2004

46. Park, D. H.; Park, S. S.; Choe, S. J.; Bull. Korean Chem. Soc. 1999, 20 , 293.

47. Khan, R.; Kim, S. W.; Kim, T.-J.; Lee, H.; Bull. Korean Chem. Soc. 2007, 28, 1951

48. Dai, S.; Chem. Eur. J. 2001, 7, 763.

49. Dai, S.; Shin, Y. S.; Barnes, C. E.; Toth, L. M.; Chem. Mater. 1997, 9 , 2521.

50. Dai, S.; Burleigh, M. C.; Ju, Y. H.; Gao, H. J.; Lin, J. S.; Pennycook, S. J.; Barnes, C. E.; Xue, Z. L.; J. Am. Chem. Soc. 2000, 122, 992.

51. Hoffmann, F.; Cornelius, M.; Morell, J.; Froeba, M.; Angew. Chem. Int. Ed. 2006, 45, 3216.

52. Burleigh, M. C.; Dai, S.; Hagaman, E. W.; Lin, J. S.; Chem. Mater. 2001, 13, 2537

53. Lu, Y. K.; Yan, X. P.; Anal. Chem. 2004, 76, 453; Wu, G.; Wang, Z.; Wang, J.; He, C.; Anal. Chim. Acta 2007, 582, 304.

54. Nacano, L. R.; Segatelli, M. G.; Tarley, C. R. T.; J. Braz. Chem. Soc. 2010, 21, 419.

55. José, N. M.; Prado, L. A. S. D. A.; Quim. Nova 2005, 28, 28.

56. Tarley, C. R. T.; Andrade, F. N.; de Santana, H.; Zaia, D. A. M.; Beijo, L. A.; Segatelli, M. G.; React. Funct. Polym. 2012, 72, 83

57. Makote, R. D.; Dai, S.; Anal. Chim. Acta 2001, 435, 169.

58. Tarley, C.R.T.; Andrade, F.N.; Oliveira, F.M.; Corazza, M.A.; Azevedo, L.F.M.; Segatelli, M.G.; Anal. Chim. Acta 2011, 703, 145.

59. Bi, X.; Lau, R. J.; Yang, K.-L.; Langmuir 2007, 23, 8079.

60. Jiang, N.; Chang, X.; Zheng, H.; He, Q.; Hu, Z.; Anal. Chim. Acta 2006 , 577, 225; Chang, X.; Jiang, N.; Zheng, H.; He, Q.; Hu, Z.; Zhai, Y.; Cui, Y.; Talanta 2007, 71, 38; Fan, H.-T.; Li, J.; Li, Z.-C.; Sun, T.; Appl. Surf. Sci. 2012, 258, 3815; de Avila, T. C.; Segatelli, M. G.; Beijo, L. A.; Tarley, C. R.T.; Quim. Nova 2010, 33, 2; Zhu, X.; Cui, Y.; Chang, X.; Zou, X.; Li, Z.; Microchim. Acta 2009, 164, 125.

61. Boscott, R. J.; Nature 1947, 159, 342.

62. Qin, S. H.; Qin, D. Q.; Ford, W. T.; Resasco, D. E.; Herrera, J. E.; Macromol. 2004, 37, 752; Bens, E. M.; Anal. Chem. 1961, 33, 178.

63. Guo, M.; Xia, J.; Fan, Z.; Zhao, Z.; Mi, H.; J. Appl. Polym. Sci. 2009, 113, 3954; Tonhi, E.; Collins, K. E.; Jardim, I.; Collins, C. H.; Quim. Nova 2002, 25, 616; Quaglia, M.; De Lorenzi, E.; Sulitzky, C.; Caccialanza, G.; Sellergren, B.; Electrophoresis 2003, 24, 952.

64. Bridgeford, D. J.; Ind. Eng. Chem. Res. 1962, 1, 45.

65. Andreyeva, G. A.; Mitsengendler, S. P.; Sokolova, K. I.; Korotkov, A. A.; Polym. Sci. U.S.S.R. 1966, 8, 2391; Chapiro, A.; Stannett, V.; J. Chim. Phys. Phys.- Chim. Biol. 1960, 57, 35; Puig, J. R.; Dobo, J.; Int. J. Appl. Radiat. Isot. 1961, 10, 112. Kudrna, S. K.; Polym. Sci. U.S.S.R. 1965, 7 , 617.

66. Avny, Y.; Zilkha, A.; Eur. J. Chem. 1966, 2, 367; Avny, Y.; Migdal, S.; Zilkha, A.; Eur. J. Chem. 1966, 2, 355.

67. Turmanova, S.; Trifonov, A.; Kalaijiev, O.; Kostov, G.; J. Membr. Sci. 1997, 127, 1; Hsiue, G. H.; Wang, C. C.; Biotechnol. Bioeng. 1990, 36, 811; Dmitrenko, A. V.; Shadrina, N. E.; Ivanchev, S. S.; Ulinskaya, N. N.; Volkov, A. M.; J. Chromatogr. 1990, 520, 21; Viklund, C.; Svec, F.; Frechet, J. M. J.; Irgum, K.; Biotechnol. Progr. 1997, 13, 597.

68. Chang, Y. C.; Frank, C. W.; Langmuir 1996, 12, 5824.

69. Gao, B. J.; An, F. Q.; Zhu, Y.; Polymer 2007, 48, 2288

70. Zayats, M.; Lahav, M.; Kharitonov, A. B.; Willner, I.; Tetrahedron 2002, 58,815 .

71. Gao, B. J.; An, F. Q.; Liu, K. K.; Appl. Surf. Sci. 2006, 253,1946.

72. Gasparrini, F.; Misiti, D.; Rompietti, R.; Villani, C.; J. Chromatogr. A 2005, 1064, 25; Shamsipur, M.; Fasihi, J.; Ashtari, K.; Anal. Chem. 2007, 79, 7116 
73. Li, F.; Du, P.; Chen, W.; Zhang, S. S.; Anal. Chim. Acta 2007, 585, 211.

74. Wilson, D.; Arada, M. A.; Alegret, S.; del Valle, M.; J. Hazard. Mater. 2010, 181, 140; Ganjali, M. R.; Motakef-Kazami, N.; Faridbod, F.; Khoee, S.; Norouzi, P.; J. Hazard. Mater. 2010, 173, 415.

75. Dickert, F. L.; Lieberzeit, P.; Tortschanoff, M.; Sens. Actuators, B 2000 65, 183; Hirayama, K.; Sakai, Y.; Kameoka, K.; Noda, K.; Naganawa, R.; Sens. Actuators, B 2002, 86, 20; Haupt, K.; Mosbach, K.; Chem. Rev. 2000, 100, 2495; Ansell, R. J.; Kriz, D.; Mosbach, K.; Curr. Opin. Biotechnol. 1996, 7, 89; Li, W.; Li, S.; Olig. Pol. Comp. Mol. Imp. 2007, 206, 191.

76. Murray, G. M.; Jenkins, A. L.; Bzhelyansky, A.; Uy, O. M.; Johns Hopkins APL Technical Digest 1997, 18, 464.

77. Wang, Z.; Liu, X.; Yang, J.; Qin, Y.; Lu, X.; Electrochim. Acta 2011, 58, 750 .

78. Alizadeh, T.; Amjadi, S.; J. Hazard. Mater. 2011, 190, 451.
79. Alizadeh, T.; Ganjali, M. R.; Nourozi, P.; Zare, M.; Hoseini, M.; J. Electroanal. Chem. 2011, 657, 98.

80. Alizadeh, T.; Ganjali, M. R.; Zare, M.; Anal. Chim. Acta 2011, 689, 52.

81. Fu, X.-C.; Wu, J.; Nie, L.; Xie, C.-G.; Liu, J.-H.; Huang, X.-J.; Anal. Chim. Acta 2012, 720, 29.

82. Guney, O.; Cebeci, F. C.; J. Appl. Polym. Sci. 2010, 117, 2373; Gao, Y.; Shen, S.; Yao, K.; pat. CN20111460517 20111231, 2012.

83. Tan, J.; Wang, H.-F.; Yan, X.-P.; Biosens. Bioelectron. 2009, 24, 3316; Mou, H.; Gao, Y.; Fu, K.; Yao, K.; Fenxi Ceshi Xuebao 2011, 30, 795.

84. Guney, O.; Yilmaz, Y.; Pekcan, O.; Sens. Actuators, B 2002, 85,86.

85. Al-Kindy, S.; Badia, R.; Diaz-Garcia, M. E.; Anal. Lett. 2002, 35, 1763; Ng, S. M.; Narayanaswamy, R.; Anal. Bioanal. Chem. 2006, 386, 1235.

86. Pinheiro, S. C. L.; Descalzo, A. B.; Raimundo, I. M.; Orellana, G.; Moreno-Bondi, M. C.; Anal. Bioanal. Chem. 2012, 402, 3253; Ng, S.M.; Narayanaswamy, R.; Microchim. Acta 2010, 169, 303. 